Research Article

\title{
Study on the Annual Reduction Rate of Vehicle Emission Factors for Carbon Monoxide: A Case Study of Urban Road Tunnels in Shenzhen, China
}

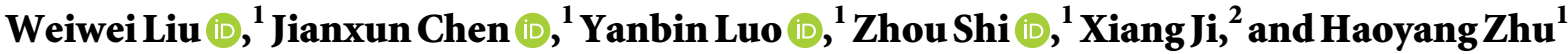 \\ ${ }^{1}$ School of Highway, Chang'an University, Xi'an 710064, China \\ ${ }^{2}$ China Construction Eighth Engineering Division Co. Ltd., Shanghai 200135, China
}

Correspondence should be addressed to Jianxun Chen; chenjx1969@chd.edu.cn and Yanbin Luo; lyb@chd.edu.cn

Received 16 April 2019; Revised 12 July 2020; Accepted 7 August 2020; Published 3 September 2020

Academic Editor: Chunshun Zhang

Copyright (c) 2020 Weiwei Liu et al. This is an open access article distributed under the Creative Commons Attribution License, which permits unrestricted use, distribution, and reproduction in any medium, provided the original work is properly cited.

\begin{abstract}
Environmental pollution and energy conservation in urban tunnels have become important issues that affect the scientific design and sustainable development of urban tunnels. The carbon monoxide (CO) concentration in urban road tunnels is regarded as a direct reflection and a useful tracer of the intensity of anthropogenic transportation activities. Previous studies in recent years have paid more attention to pollutant emission factors, but less to the calculation parameters of ventilation design for tunnels. This paper aims to study a reasonable annual reduction rate of CO base emission factors. Therefore, a detailed field measurement was carried out in the four typical urban road tunnels, Henglongshan Tunnel, Cejiexian Tunnel, Jiuweiling Tunnel, and Dameisha Tunnel in Shenzhen, China, from March 29 to September 16, 2014. Measurement results showed that the traffic flow of the four urban tunnels had been approaching the design value, or even beyond the limit. The average daily air velocities in the four tunnels were all within $5 \mathrm{~m} / \mathrm{s}$, whereas the maximum air velocity had exceeded the limit of $10 \mathrm{~m} / \mathrm{s}$. The CO concentrations in Henglongshan Tunnel, Cejiexian Tunnel, Jiuweiling Tunnel, and Dameisha Tunnel were $17 \mathrm{ppm}, 7 \mathrm{ppm}, 39 \mathrm{ppm}$, and 8 ppm, respectively. Moreover, it was found that the average CO emission factors of Henglongshan Tunnel, Cejiexian Tunnel, Jiuweiling Tunnel, and Dameisha Tunnel were $1.075 \mathrm{~g} /(\mathrm{km} \cdot \mathrm{veh}), 1.245 \mathrm{~g} /(\mathrm{km} \cdot \mathrm{veh}), 4.154 \mathrm{~g} /(\mathrm{km} \cdot \mathrm{veh})$, and $1.739 \mathrm{~g} /(\mathrm{km} \cdot \mathrm{veh})$, respectively. Based on the statistical data, the CO emission factors of mixed traffic and passenger cars decrease by an average of $16.4 \%$ and $33.3 \%$, respectively, per year through the regression method and by an average of $17.4 \%$ and $29.0 \%$, respectively, per year through the extremum method. Finally, when considering the safety factor of $20 \%$, it is more reasonable for the CO base emission to adopt $4 \%$ as an annual reduction rate for ventilation design in urban tunnels.
\end{abstract}

\section{Introduction}

With the rapid development of economic construction and transportation infrastructure in China, a large number of tunnels have been or will be constructed in the coming years [1-11]. However, the in-tunnel environmental pollution during the tunnel service period has become an important problem restricting the development of tunnels, especially urban tunnels. In the past few decades, the vehicle population in China has been experiencing explosive growth, for example, from 231.63 million in 2013 to 307.447 million in 2018 , with an average annual growth of 5.8\% [12]. Meanwhile, China has been experiencing increasing air pollution with the rapid industrialization and urbanization, especially in the densely populated southeast areas, such as the Yangtze River Delta economic zone and the Pearl River Delta Economic Zone. As a kind of urban linear structure, urban road tunnel is regarded as the chimney of urban air pollution, and the environmental pollution issue in the urban road tunnel has been increasingly arising great concern. The air pollutants in urban tunnels mainly come from the vehicle exhaust in anthropogenic transport activities, and CO gas is one of the most influential pollutants. The vehicle tailpipe emissions contain many harmful components, including $\mathrm{CO}, \mathrm{NO}_{2}, \mathrm{~Pb}, \mathrm{CO}_{2}, \mathrm{SO}_{2}, \mathrm{HCHO}$, and smoke, among which $\mathrm{CO}$ is considered to be the highest content and the most 
harmful pollutant to human health. CO is a kind of colorless, odorless, and toxic gas produced by incomplete combustion of fossil fuel. Due to the semiclosed structure of the tunnel, $\mathrm{CO}$ is not easy to be discharged quickly from the tunnel, but it is easy to accumulate. Once the $\mathrm{CO}$ concentration accumulates to a certain extent, drivers and passengers in the tunnel will suffer from physical discomfort or even suffocation death.

$\mathrm{CO}$ concentration is a significant controlling factor for the calculation of fresh air demand in tunnels. Especially in the ventilation calculation for urban road tunnels, due to the traffic features of large traffic flow, low vehicle speed, and dominant proportion of light-duty vehicles, the fresh air demand is basically determined by CO concentration among many pollutants. The fresh air demand for tunnel ventilation directly affects the ventilation scheme, the scale of the ventilation system, and the cost of construction and operation. China's current tunnel ventilation design code stipulates that the $\mathrm{CO}$ concentration should adopt $100 \mathrm{ppm}$ as the design limit in normal conditions for the tunnel whose length is not less than $3000 \mathrm{~m}$ and $150 \mathrm{ppm}$ for congested condition within $20 \mathrm{~min}$ exposure time [13]. However, ample research studies have shown that the CO concentrations in operating tunnels are far below the design level [14-22]. The high design standard makes a considerable number of tunnels equipped with large-scale or even luxurious ventilation facilities in China, while the in-tunnel low pollutant concentrations, especially the $\mathrm{CO}$ concentration, make managers operate fewer or no ventilation equipment. This contradiction makes the ventilation equipment have failed to play their due role since being put into use, which inevitably results in a waste of facility resources and go against the concepts of energy-saving and sustainable development. Therefore, the overdesign of the ventilation system has been a universal and serious problem. The reasons behind the overdesign of the tunnel ventilation system are the excessive calculation of pollutant emissions and irrationality of calculation parameters. And a reasonable time factor of base emissions, also known as annual reduction rate in China, may effectively prevent the waste and contradiction.

In essence, the calculation of fresh air demand is a prediction of air demand for diluting the pollutants in tunnels for future years. There are differences on the air demand calculation between China and PIARC. In China, a fixed base emission factor in a base year (such as the base year 2000 specified in the current ventilation specification) and a fixed annual reduction rate (such as $2 \%$ specified in the current ventilation specification) are used to calculate the total pollutant emissions and fresh air demands for future years [13]. The base emission factor usually refers to the pollutant emission from a passenger car when the driving speed remains $60 \mathrm{~km} / \mathrm{h}$ and the road gradient is $0 \%$. In PIARC, the total pollutant emissions are calculated based on the base emission factors and influence factors (variables provided in the PIARC report) for years differing from the base year, and the base emission factor varies with the average traffic speed and road gradient $[23,24]$. Therefore, it is indicated that the annual reduction rate is of great significance to tunnel ventilation calculation in China; it represents the average reduction rate of $\mathrm{CO}$ base emission factors. And whether the annual reduction rate is reasonable or not directly affects the calculation accuracy of total $\mathrm{CO}$ emissions and fresh air demand.

Previous studies in recent years have focused more on vehicle emission factors in China. Yang et al., Yao et al., and He et al. studied the vehicle exhaust emission characteristics at different speeds through bench test and road test [25-27]. Ho et al.,, Liu and Gao, and Deng et al. investigated the pollutant emission performance of various vehicle types by the tunnel measurement method [28-30]. Based on emission models and investigations of relevant fundamental data, Song and Xie, Cai and Xie, and Lang et al. established vehicular emission inventories and contribution rates in typical cities [31-33]. Fu et al., He et al., and Xie et al. systemically analyzed the structures of emission models and attempted to develop a method of localization for emission models, such as mobile, CEME, and COPERT [34-36]. However, limited research studies have been reported at this point concerning the annual reduction rate of base emissions. The old version of tunnel ventilation specification released in 2000 by the "Ministry of Communications of the People's Republic of China" stipulated that the CO base emission used 1995 as the base year and took 1\% 2\% as the annual reduction rate [37]. Wang et al. studied the CO emission characteristics at different vehicle speeds through bench experiment and road testing, and the test results showed that the CO base emission of $0.01 \mathrm{~m}^{3} /(\mathrm{km} \cdot \mathrm{veh})$ in the base year 1995 specified in the old ventilation specification was relatively high [38]. However, the research did not take annual reduction rate into account to avoid overdesign of the base emission for the design year. Based on the analysis of vehicle exhaust pollutant components and the EU automobile emission standard limits, Guo et al. pointed out that the $\mathrm{CO}$ emissions of diesel and gasoline vehicles would cumulatively reduce by $81.62 \%$ and $63.24 \%$, respectively, from 2000 to 2025, with an average annual decrease of $6.31 \%$ and $3.78 \%$, respectively, and it tended to be conservative in terms of the reduction factor of $1 \% \sim 2 \%$, which was stipulated in the previous ventilation specification for tunnels [39]. The new version of ventilation specification released in 2014 by the "Ministry of Transport of the People's Republic of China" specified that the CO base emission used 2000 as the base year and took $2 \%$ as the annual reduction rate [13]. Under the conditions of $60 \mathrm{~km} /$ $\mathrm{h}$ and 0 gradient, the $\mathrm{CO}$ base emission factor for a gasoline passenger car given by PIARC decreased by $85 \%$ from $68.2 \mathrm{~g} / \mathrm{h}$ in 2010 to $18.2 \mathrm{~g} / \mathrm{h}$ in 2018 , with an average annual reduction rate of $15 \%[23,24]$. The average annual reduction rates of $\mathrm{CO}$ emission factors for the gasoline passenger car and diesel passenger car are $4.5 \%$ and $2.8 \%$, respectively, by 2030 with a base year being defined as 2010 , and they are $2.5 \%$ and $2.2 \%$, respectively, by 2035 with a base year being defined as 2018 [23, 24]. Based on the environmental measurement in the urban tunnels of Shenzhen, Luo et al. recommended using $8 \%$ as the annual reduction rate of $\mathrm{CO}$ emission factors through the backcalculation method [40]. 
As the front window of China's reform and opening up, Shenzhen has been maintaining a rapid and healthy development of the economy, and the number of motor vehicles has increased rapidly. By the end of 2014, the vehicle population of Shenzhen had exceeded 3 million, coupled with 200 thousand temporary transit vehicles through the downtown of Shenzhen. A huge number of vehicles have become the main source of urban air pollution. Therefore, in order to determine the environmental pollution inside urban tunnels and $\mathrm{CO}$ emission factors of motor vehicles, four typical urban road tunnels were carefully selected for environmental monitoring from March 29 to September 16, 2014, in Shenzhen. The results of this paper could provide data support for further studies on the emission characteristics of pollutants from motor vehicle exhaust and emission inventories of air pollutants in urban areas and offer references for the reasonable annual reduction rate of $\mathrm{CO}$ base emissions by comparing $\mathrm{CO}$ emission factors in different years.

\section{Methodology}

2.1. Tunnel Description. Based on the field surveys and material collection of more than 30 urban road tunnels in Shenzhen, the four representative tunnels of Henglongshan Tunnel, Cejiexian Tunnel, Jiuweiling Tunnel, and Dameisha Tunnel were carefully selected to collect data on traffic volume, air velocity, and $\mathrm{CO}$ concentration. These four urban road tunnels represent the urban arterial road, Shenzhen-Hong Kong transit corridor, urban expressway, and urban tourism area expressway, respectively. They are located in different areas of Shenzhen with various vehicle fleet composition characteristics and play different roles in the urban traffic network (Figure 1). The main technical parameters of the four tunnels are listed in Table 1.

2.2. Sampling and Instruments. The traffic survey was carried out by setting up a monitoring station at the entrance or inside of each tunnel. 9 or 10 fixed stations were positioned along the traffic direction for air velocity monitoring. The CO concentration sampling sites were arranged near the tunnel exit instead of the whole tunnel because the $\mathrm{CO}$ concentrations were basically $0 \mathrm{ppm}$ at the entrance sites at the beginning of measurement. The air velocity and $\mathrm{CO}$ concentration shared a monitoring station at the same position, and the monitoring stations were $1.5 \mathrm{~m}$ above the maintenance path and $0.2 \mathrm{~m}$ away from the pavement. The station position in cross section is shown in Figure 2. The temperature and atmospheric pressure were measured inside and outside of each tunnel, respectively. The air velocity measurement and $\mathrm{CO}$ concentration measurement performed synchronously and sampled data every 3 minutes automatically. The sampling sites of four tunnels are shown in Figure 3. Each tunnel was continuously monitored for 2-7 days, and the whole test lasted from March 29 to September 16, 2014.

The traffic flow and vehicle speed were continuously measured by photographic counting equipment. Traffic survey includes the traffic volume, traffic speed, traffic composition, and proportion of gasoline and diesel vehicles. The air velocity inside the tunnel was monitored continuously by using the AZ9871 anemometer with the sensitivity of $0.1 \mathrm{~m} / \mathrm{s}$ and $3 \mathrm{~min}$ time resolution. The anemometer provides a brief and user-friendly operation interface and can be used for long-term automatic monitoring. The temperature and the atmospheric pressure inside and outside the tunnel were measured by the DYM3-type emptybox barometer with $1.0^{\circ} \mathrm{C}$ temperature resolution and $1.0 \mathrm{hPa}$ pressure resolution. The instrument has the advantages of high accuracy, wide measuring range, and portability. The CO detector (TES-1372R) was used for continuously monitoring $\mathrm{CO}$ concentration with the sensitivity of $1 \mathrm{ppm}$ and $3 \mathrm{~min}$ time resolution. The instrument works via a high-stability electrochemical $\mathrm{CO}$ sensor and supports automatic recording or manual recording. All instruments were calibrated by the professional organizations before and after measurement.

\subsection{Analysis Method}

2.3.1. Vehicle Emission Factor. The relationship between concentration distribution and emission rate of pollutants, emitted into the air by the automobile engine in tunnels, can be analyzed by the one-dimensional steady-state transport equation. The direction of air flow in the tunnel is taken as the $x$-axis, and the air inlet of the tunnel is defined as the starting point of the $x$-axis. Thus, without considering the chemical reaction decay process of pollutants from vehicle emissions, the average vehicle emission factor can be expressed as the following equation:

$$
\mathrm{EF}_{j}=3600 A V \frac{\partial C_{j} / \partial x}{\sum_{i=1}^{n} N_{i}} \approx 3600 A V \frac{\Delta C_{j} / \Delta x}{\sum_{i=1}^{n} N_{i}},
$$

where $\mathrm{EF}_{j}$ is the average vehicle emission factor of pollutant $j, \mathrm{~g} /(\mathrm{km} \cdot \mathrm{veh}) ; A$ is the cross-sectional area, $\mathrm{m}^{2} ; V$ is the mean air velocity in the $x$-axis direction, $\mathrm{m} / \mathrm{s} ; C_{j}(x)$ is the concentration of pollutant $j, \mathrm{mg} / \mathrm{m}^{3}$; and $N_{i}$ is the number of vehicle $i$, veh/h.

The average emission factor reflects the mean level of the vehicle tailpipe emission for a specific pollutant in the case of overall considering the traffic speed, traffic composition, vehicle age distribution, and vehicle mileage distribution.

2.3.2. Estimated Total Emissions. The weight mean of average annual vehicle mileage is expressed by the following equation:

$$
M=\frac{1}{100} \sum_{i}\left(m_{i} \cdot p_{i}\right)
$$

where $M$ is the average annual vehicle kilometers traveled, $\mathrm{km} /$ year; $m_{i}$ is the average annual kilometers of vehicle $i$ traveled, $\mathrm{km} /$ year; and $p_{i}$ is the traffic composition of vehicle $i, \%$.

And the estimated total vehicle emissions of pollutant $j$ are expressed by the following equation: 


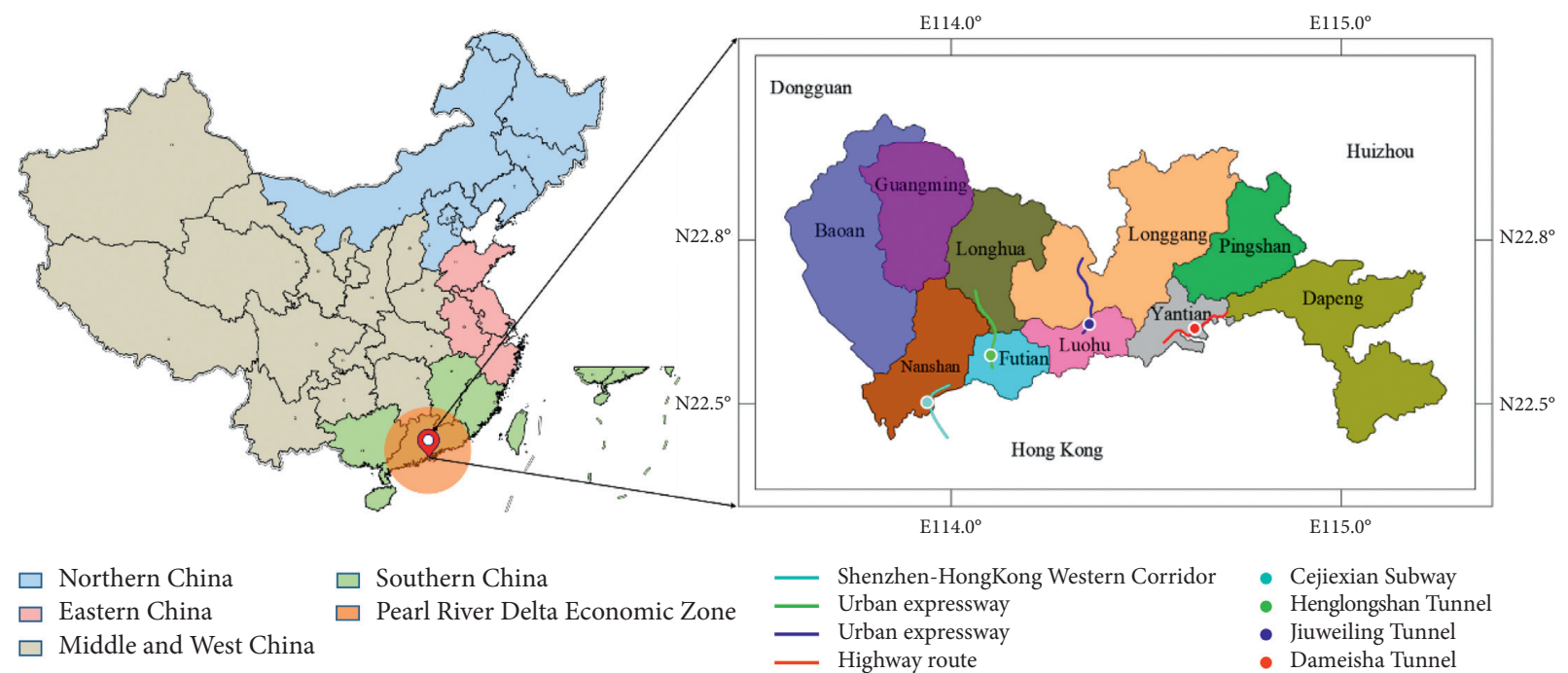

Figure 1: The study area and case tunnel locations.

TABLE 1: Main design parameters of the four tunnels.

\begin{tabular}{|c|c|c|c|c|c|}
\hline Tunnel name & Location & Length (m) & $\begin{array}{c}\text { Design speed } \\
(\mathrm{km} / \mathrm{h})\end{array}$ & Road grade & Ventilation design \\
\hline $\begin{array}{l}\text { Henglongshan } \\
\text { Tunnel }\end{array}$ & Fulong Road & $\begin{array}{l}\text { Left bore: } \\
2330 \\
\text { Right bore: } \\
2275\end{array}$ & 60 & $\begin{array}{l}\text { Urban expressway (two-bore } \\
\text { six-lane) }\end{array}$ & $\begin{array}{c}\text { Main tunnels: } 24 \text { jet fans } \\
\text { Ramps: } 6 \text { jet fans }\end{array}$ \\
\hline Cejiexian Tunnel & $\begin{array}{c}\text { Shenzhen Western } \\
\text { Corridor }\end{array}$ & $\begin{array}{l}\text { Main bore: } \\
\quad 4480\end{array}$ & 80 & Highway (two-bore six-lane) & $\begin{array}{l}\text { Left bore: } 100 \text { jet fans } \\
\text { Right bore: } 66 \text { jet fans }\end{array}$ \\
\hline Jiuweiling Tunnel & Danping Expressway & $\begin{array}{l}\text { Left bore: } \\
1472 \\
\text { Right bore: } \\
1447 \\
\end{array}$ & 80 & $\begin{array}{l}\text { Urban expressway (two-bore } \\
\text { six-lane) }\end{array}$ & $\begin{array}{l}\text { Left bore: } 1 \text { shaft and } 6 \text { jet } \\
\text { fans } \\
\text { Right bore: } 22 \text { jet fans }\end{array}$ \\
\hline Dameisha Tunnel & Dameisha Road & $\begin{array}{l}\text { Left bore: } \\
1521 \\
\text { Right bore: } \\
1540\end{array}$ & 60 & Highway (two-bore six-lane) & $\begin{array}{l}\text { Left bore: } 12 \text { jet fans } \\
\text { Right bore: } 6 \text { jet fans }\end{array}$ \\
\hline
\end{tabular}

$$
Q_{j}=M \cdot P_{j} \cdot \mathrm{EF}_{j} \cdot 10^{-6}
$$

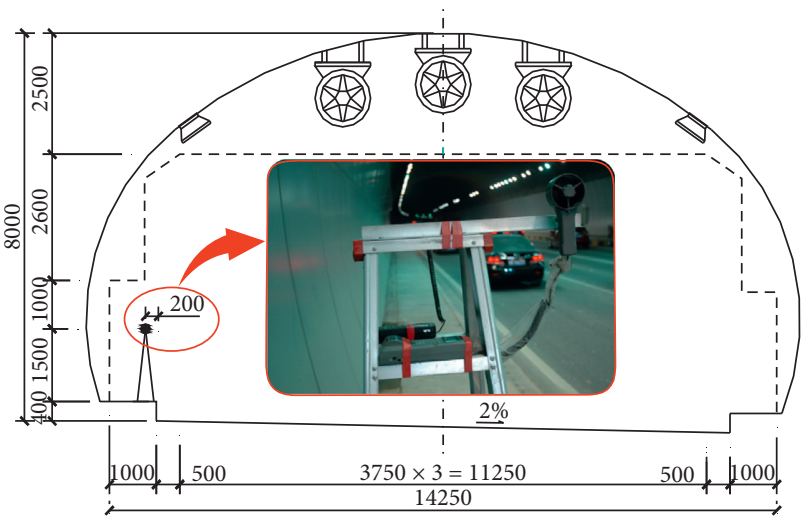

FIGURE 2: The monitoring station position in cross section (unit: $\mathrm{mm}$ ). where $Q_{j}$ is the total vehicle emissions of pollutant $j$, ton/ year; $P_{j}$ is the vehicle population in the statistic year; and $\mathrm{EF}_{j}$ is the average vehicle emission factor for pollutant $j$, $\mathrm{g} /(\mathrm{km} \cdot \mathrm{veh})$.

2.3.3. Annual Reduction Rate. As the CO emission projections for future years are influenced by fleet renewal of vehicles with more stringent emission standards taken into account, the CO base emission factor in the design year is calculated by the base emission factor of the base year at a fixed annual reduction rate in China, as shown in the following equation:

$$
q_{\mathrm{CO}, n_{0}} \cdot(1-\omega)^{n_{i}-n_{0}}=q_{\mathrm{CO}, n_{i}},
$$




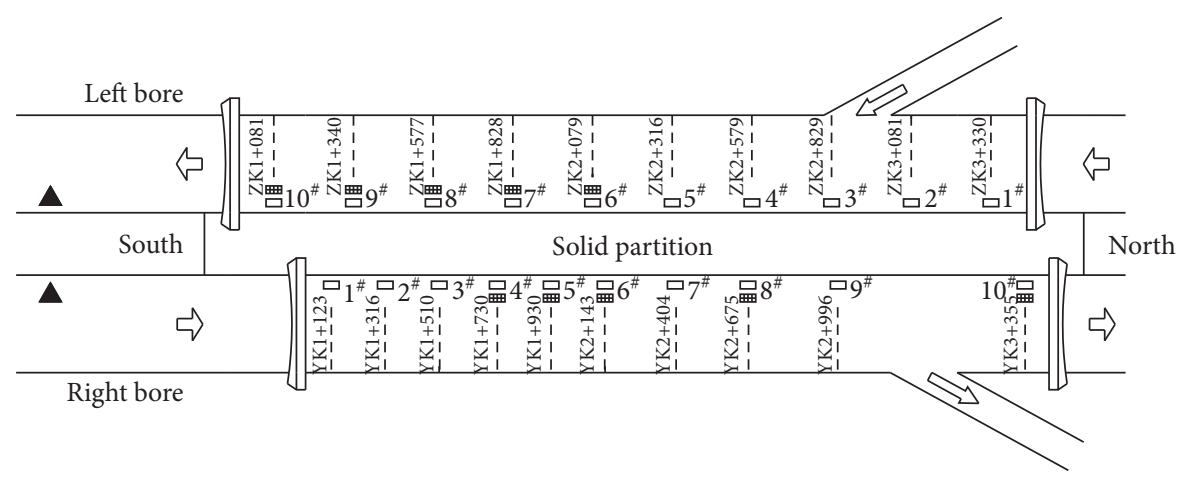

ㅁ Air velocity

m $\mathrm{CO}$ concentration

A Traffic volume sampling site

(a)

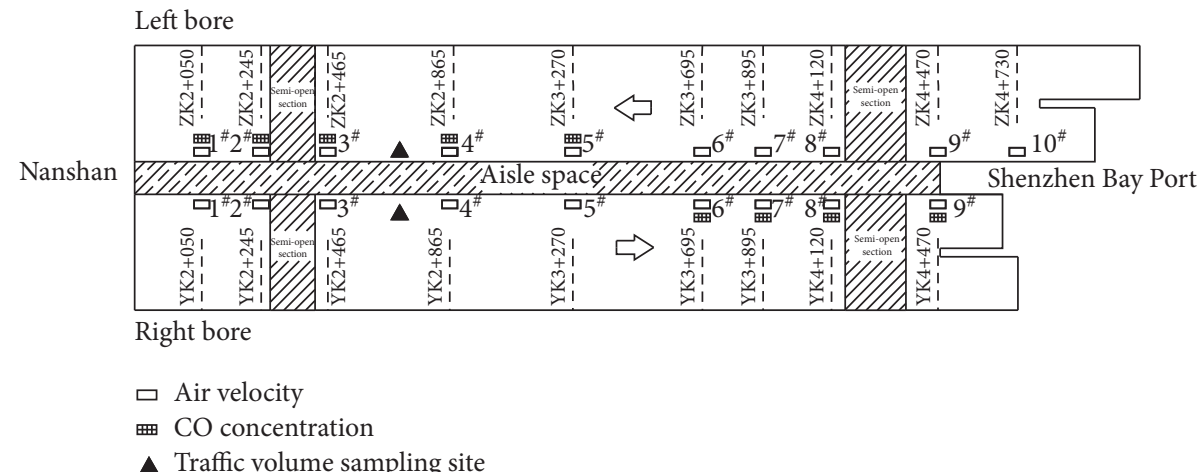

(b)

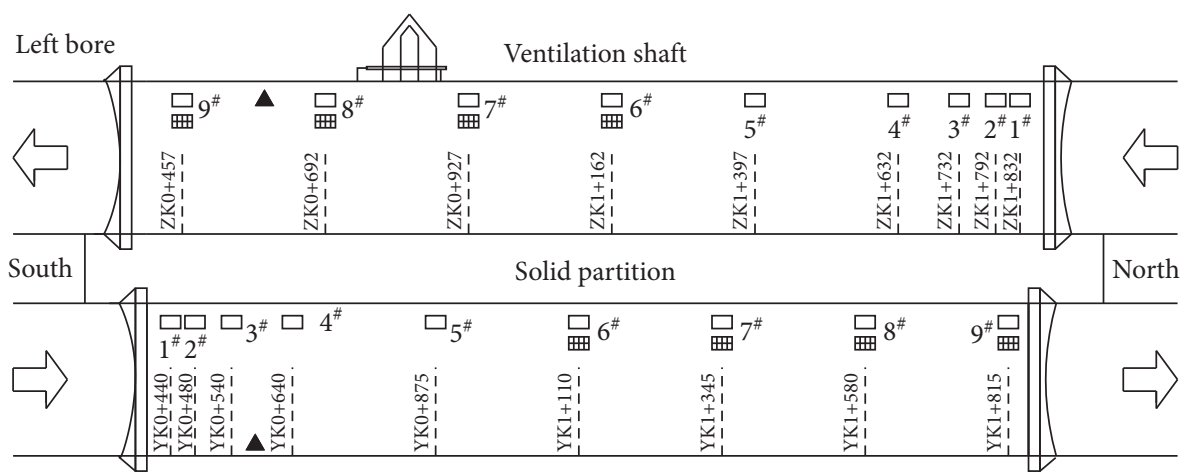

Right bore

$\square$ Air velocity

曲 CO concentration

- Traffic volume sampling site

(c)

FIgURE 3: Continued. 


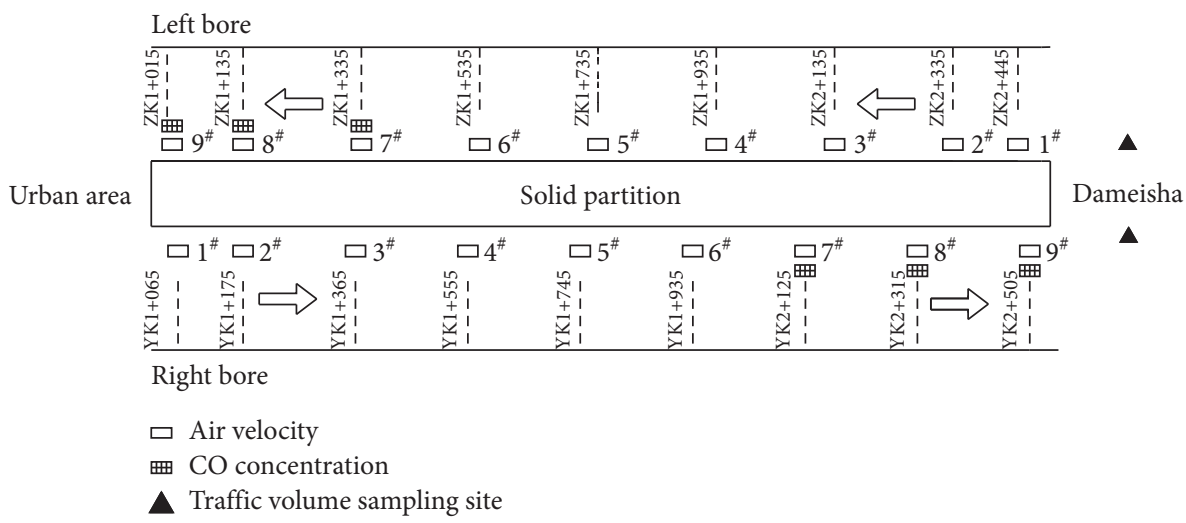

(d)

Figure 3: The sampling point distribution in the four tunnels. (a) Henglongshan Tunnel. (b) Cejiexian Tunnel. (c) Jiuweiling Tunnel. (d) Dameisha Tunnel.

where $q_{\mathrm{CO}, n_{0}}$ is the $\mathrm{CO}$ base emission factor in the base year, $\mathrm{m}^{3} /(\mathrm{km} \cdot \mathrm{veh}) ; \omega$ is the annual reduction rate for the years differing from the base year; $q_{\mathrm{CO}, n_{i}}$ is the $\mathrm{CO}$ base emission factor in the design year, $\mathrm{m}^{3} /(\mathrm{km} \cdot \mathrm{veh}) ; n_{0}$ is the base year; and $n_{i}$ is the future design year.

Therefore, the annual reduction rate of the $\mathrm{CO}$ base emission factor in the future design year can be determined by the following equation:

$$
\omega=1-\left(\frac{q_{\mathrm{CO}, n_{i}}}{q_{\mathrm{CO}, n_{0}}}\right)^{1 /\left(n_{i}-n_{0}\right)} .
$$

\section{Results and Discussion}

\subsection{Measurement Results}

3.1.1. Traffic Characteristics. Based on the continuous observation of traffic flow in the four urban tunnels, the survey results were statistically analyzed and compared with the original design data. Table 2 reveals a fact that the traffic volume of the four tunnels has been approaching the original design values, even beyond the limits. The average daily traffic volume had already exceeded the design limits, except the Cejiexian Tunnel. In particular, the daily traffic volume of the left bore and right bore of Henglongshan Tunnel was far in excess of $41,000 \mathrm{pcu} / \mathrm{d}$, beyond the design value by $57 \%$ and $74 \%$, respectively. And due to the dramatic increase in traffic flow during the official holidays, the left bore of Dameisha Tunnel had reached the upper limit of its traffic capacity during the Mid-Autumn Festival. The average peak traffic volume was closing to their design limits, especially Henglongshan Tunnel. Urban tunnels had become the bottlenecks of urban transportation and showed saturated condition frequently. For instance, the cars had to stop and go in rush hours when passing through the Henglongshan Tunnel; during the holidays, the number of tourist vehicles, traveling from and to Dameisha Beach (a famous tourist attraction in Shenzhen) through the Dameisha Tunnel, rose explosively with daily traffic growth of $12,759 \mathrm{pcu} / \mathrm{d}$ and $11,820 \mathrm{pcu} / \mathrm{d}$ for the left and right bores, respectively, which led to the phenomenal congestion in Dameisha Tunnel; and about $300 \mathrm{~m}$ from the south outlet of the Jiuweiling Tunnel was a junction, and one of the three lanes in the left bore was closed as a rescue channel, all of which restricted its traffic capacity. Therefore, a considerable number of urban tunnels with congested traffic have greatly affected the comfort of driving, deteriorated the level of road service, and reduced the traffic capacity.

Figure 4 shows that the passenger cars contribute a large proportion to the traffic flow of urban tunnels, and it accounts for $75 \% \sim 81 \%$ of the total traffic. Due to the differences of the geographical location and transportation function of urban tunnels, the traffic composition of each tunnel was different, even two bores of one tunnel had considerable differences. As illustrated in Figure 5, the number of gasoline vehicles was far more than that of diesel vehicles; the former comprised about $70 \%$ of the total traffic fleet and the latter only $30 \%$.

3.1.2. Air Velocity. The meteorological parameters were measured at various sampling sites for at least 2 days in each tunnel, which included the air velocity, temperature, and atmospheric pressure. Table 3 shows the statistical results of meteorological parameters. During the sampling period, the main wind direction was consistent with the vehicle moving direction. The average air velocities of four tunnels were all within $5 \mathrm{~m} / \mathrm{s}$. There were notable differences between the left bore and right bore of a tunnel, which mainly resulted from the differences in the traffic volume and natural wind. The maximum air velocities of Henglongshan Tunnel, Cejiexian Tunnel, and Dameisha Tunnel were beyond the limit of $10 \mathrm{~m} / \mathrm{s}$, the biggest of which peaked at $11.0 \mathrm{~m} / \mathrm{s}$. The air velocities of Henglongshan Tunnel and Dameisha Tunnel had a larger fluctuation over time without fans opened. Under the condition of opening fans only at the peak hours, the air velocities of Cejiexian Tunnel and the right bore of Jiuweiling Tunnel fluctuated greatly, and the air velocities of the left bore of Jiuweiling Tunnel varied relatively gently. The diurnal variation curves of air velocity in tunnels are shown in Figures 6 and 7. The air velocity fluctuated greatly at 
TABLE 2: Traffic survey results of the four tunnels.

\begin{tabular}{|c|c|c|c|c|c|}
\hline \multirow{2}{*}{ Tunnel name } & \multicolumn{2}{|c|}{ Daily traffic volume (pcu/d) } & \multicolumn{2}{|c|}{ Peak traffic volume $(\mathrm{pcu} / \mathrm{h})$} & \multirow{2}{*}{ Remarks } \\
\hline & Measured value & Designed value & Measured value & Designed value & \\
\hline \multirow{2}{*}{ Henglongshan Tunnel } & 64,314 & 41,000 & 4679 & 5000 & \\
\hline & 71,535 & & 4708 & & \\
\hline \multirow{2}{*}{ Cejiexian Tunnel } & 20,776 & 39,000 & 1886 & 4757 & \\
\hline & 20,780 & & 2228 & & \\
\hline \multirow{2}{*}{ Jiuweiling Tunnel } & 32,753 & - & 1967 & - & \multirow{2}{*}{ One lane of the left bore was closed } \\
\hline & 37,641 & & 2237 & & \\
\hline \multirow{4}{*}{ Dameisha Tunnel } & 32,626 & 44,405 & 2667 & 5400 & \multirow{4}{*}{ Nonholiday period } \\
\hline & 31,884 & & 2756 & & \\
\hline & 45,385 & & 4119 & & \\
\hline & 43,704 & & 3438 & & \\
\hline
\end{tabular}

Note. Measured data consist of traffic volume of both left bore and right bore; designed data refer to one-way traffic for a single hole.

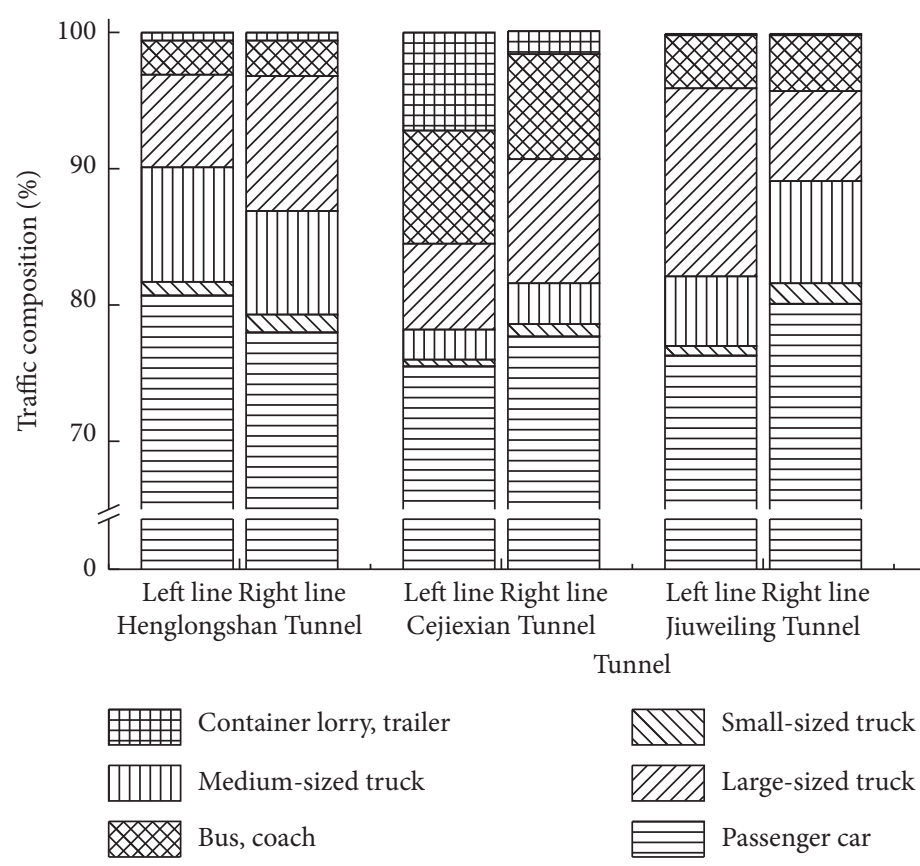

Figure 4: Traffic composition of the four tunnels.

daytime and relatively smoothly at nighttime periodically. The air velocity increased with the rapid rise of traffic volume in the period of about 6 a.m. to 7 a.m. There was a significant positive correlation between the air velocity and the traffic volume. However, when the traffic volume accumulated to the saturated state or oversaturated state, the wind speed begun to decrease, such as the period of about 7 a.m. to 8 a.m. in Henglongshan Tunnel. The air velocity presented a negative correlation with the traffic volume. Affected by the testing time, altitude of the tunnel, and weather, the temperature and atmospheric pressure in each tunnel had been changing constantly, but the range was relatively narrow.

All four urban tunnels are unidirectional traffic tunnels. The piston wind formed by the movement of motor vehicles in a tunnel was very significant and had a profound influence on pushing airflow forward. The air velocity in the tunnel depends on the combined actions of natural wind, piston wind, and mechanical wind. Shenzhen is located on the
South China Sea and the east coast of the Pearl River Delta of China. The vast sea area connects to the South China Sea and Pacific Ocean. Shenzhen has a subtropical climate with remarkable effect of sea-land breeze. Therefore, the change of wind speed in the tunnel was greatly influenced by the external environmental meteorological conditions and the uneven distribution of traffic flow.

3.1.3. In-Tunnel CO Concentrations. CO concentrations were obtained through all-weather field monitoring, and each tunnel had been monitored continuously for more than two days. As can be seen from Table 4, the CO concentrations of four tunnels were relatively low and all within the maximum limit by comparison with the admissible concentration. The original design value of $\mathrm{CO}$ concentration is $150 \mathrm{ppm}$ under normal working condition and $250 \mathrm{ppm}$ within 20 minutes under congested condition. For the 


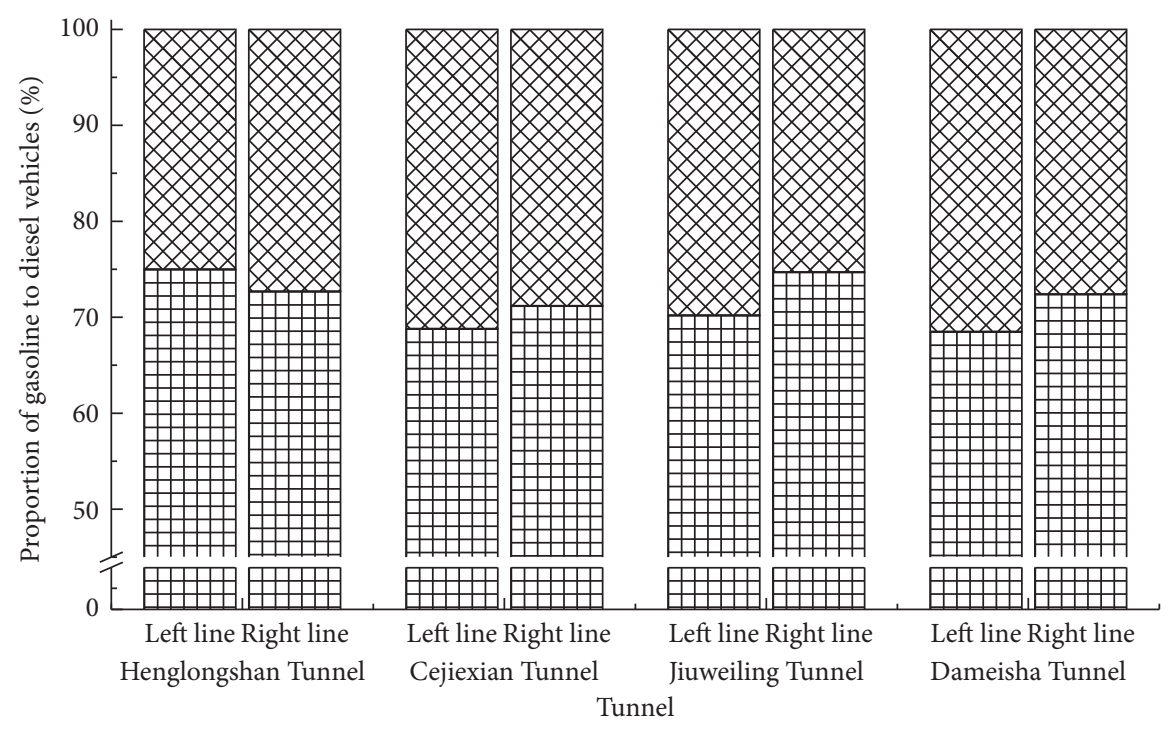

Diesel vehicles

册忸 Gasoline vehicles

FIgUre 5: Proportion of gasoline to diesel vehicles in the four tunnels.

TABLE 3: Meteorological parameters in the four tunnels.

\begin{tabular}{|c|c|c|c|c|c|c|}
\hline \multirow{2}{*}{ Tunnel name } & & \multicolumn{3}{|c|}{ Air velocity $(\mathrm{m} / \mathrm{s})$} & \multirow{2}{*}{ Temperature $\left({ }^{\circ} \mathrm{C}\right)$} & \multirow{2}{*}{ Atmospheric pressure $(\mathrm{kPa}$} \\
\hline & & Change range & Average & Standard deviation & & \\
\hline \multirow{2}{*}{ Henglongshan Tunnel } & Left bore & $0 \sim 9.2$ & 3.85 & 1.15 & $21 \sim 23$ & $100.24 \sim 101.06$ \\
\hline & Right bore & $0 \sim 10.3$ & 4.63 & 0.98 & $25 \sim 30$ & $100.79 \sim 101.23$ \\
\hline \multirow{2}{*}{ Cejiexian Tunnel } & Left bore & $0 \sim 8.4$ & 2.94 & 0.96 & $25 \sim 29$ & $100.98 \sim 101.46$ \\
\hline & Right bore & $0 \sim 10.1$ & 3.66 & 1.46 & $25 \sim 28$ & $101.31 \sim 101.54$ \\
\hline \multirow{2}{*}{ Jiuweiling Tunnel } & Left bore & $0 \sim 4.8$ & 2.06 & 0.67 & $25 \sim 27$ & $100.27 \sim 100.79$ \\
\hline & Right bore & $0 \sim 7.2$ & 3.37 & 0.90 & $25 \sim 28$ & $100.34 \sim 100.88$ \\
\hline \multirow{2}{*}{ Dameisha Tunnel } & Left bore & $0 \sim 8.1$ & 4.31 & 1.03 & $28 \sim 37$ & $100.55 \sim 101.08$ \\
\hline & Right bore & $0 \sim 11.0$ & 2.83 & 1.31 & $29 \sim 32$ & $100.22 \sim 100.65$ \\
\hline
\end{tabular}

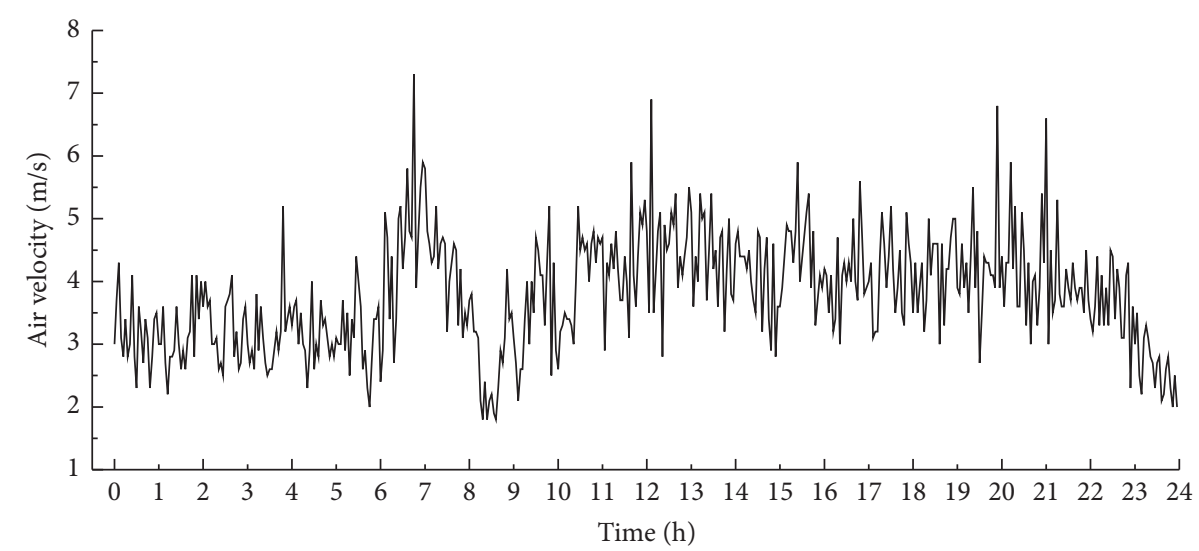

FIgURE 6: Diurnal profile of air velocity in the left bore of Henglongshan Tunnel (Apr 4, 2014).

ventilation environment of tunnels in operation, the peak values of pollutant concentrations are worthy for more attention than the mean value. The peak or maximum value can better reflect the pollution degree of vehicle emissions than using the mean value. The maximum concentration of four tunnels was $39 \mathrm{ppm}$, from the left bore of Jiuweiling Tunnel, and about $26 \%$ and $16 \%$ of the design limits, respectively, under the normal condition and congested condition. The $\mathrm{CO}$ concentrations of the other three tunnels were below $20 \mathrm{ppm}$, far less than the admissible values. 


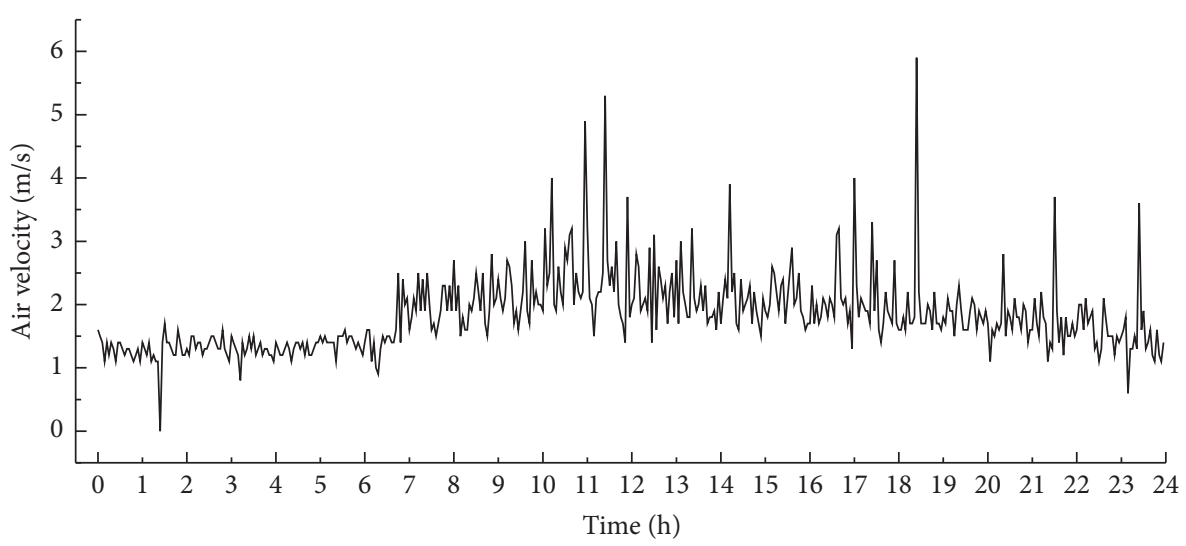

Figure 7: Diurnal profile of air velocity in the left bore of Cejiexian Tunnel (Apr 18, 2014).

TABLE 4: CO concentrations in the four tunnels (unit: ppm).

\begin{tabular}{lccccc}
\hline \multirow{2}{*}{ Tunnel name } & \multicolumn{2}{c}{ Left bore } & \multicolumn{2}{c}{ Right bore } & Ventilation equipment condition \\
& Change range & Maximum & Change range & Maximum & Closed \\
Henglongshan Tunnel & $0 \sim 17$ & 17 & $0 \sim 9$ & 9 & 6 \\
Cejiexian Tunnel & $0 \sim 7$ & 7 & $0 \sim 6$ & 9 & Open during peak hours \\
Jiuweiling Tunnel & $0 \sim 39$ & 39 & $0 \sim 9$ & 8 & Open during peak hours \\
Dameisha Tunnel & $0 \sim 6$ & 6 & $0 \sim 8$ & Closed \\
\hline
\end{tabular}

Therefore, as the in-tunnel health controlling factor, $\mathrm{CO}$ concentration has lost its true meaning, and its more prominent role is to improve the comfortableness of driving. In other words, the CO gas of vehicle exhaust emissions is within the safety limit and does not pose a risk to human health under normal ventilation condition. There are two main reasons for the result: first, with the demand for energy conservation and environmental protection increasing, more and more new energy-saving and environmentfriendly vehicles are being put into service; second, with the progress of the automobile industry, the tightening of the national automobile emission regulations, and the improvement of the fuel quality, the pollutant gases of vehicle exhaust emissions are decreasing year by year. In the aspects of the implementation of vehicle emission regulations and environmental governance, Shenzhen is at the forefront of China. It had been four years since the implementation of China IV emission standard till the measurement, which efficiently controlled vehicle pollutant emissions.

As illustrated in Figures 8 and 9, the CO concentrations of four tunnels were about $0 \mathrm{ppm}$ from 0 a.m. to 6 a.m. during the night. The reason was that the traffic volume decreases to the minimum, and $\mathrm{CO}$ emissions emitted by motor vehicles were easily diluted by natural air. There were usually two peaks in the changing curve of $\mathrm{CO}$ concentration. The peaks usually occurred about 1 hour after the rush hour, and they did not coincide with each other (Figures 10 and 11). The $\mathrm{CO}$ concentrations had been greatly influenced by the traffic flow and varied with the changes of traffic volume. The time-space effect of $\mathrm{CO}$ concentration was remarkable. The longer the tunnel was, the more time it took CO gas to move in the traffic direction. During rush hours, the traffic volume increased to a saturated or oversaturated state, resulting in a sharp increase in vehicle density and a decrease in traffic speed (as listed in Table 5). The slow speed made the piston effect weakened, and even the congested vehicle fleet had a negative effect on the movement of air flow in tunnels. As illustrated by Figure 12, the $\mathrm{CO}$ concentrations of various tunnels decreased with the increase of corresponding average hourly air velocities. All these factors led to a sharp rise in the $\mathrm{CO}$ concentration, which further resulted in the rapid deterioration of air quality in tunnels.

\subsection{CO Emission Factors of In-Use Fleet}

3.2.1. Average CO Emission Factors. In accordance with the geometric parameters of the four tunnels and a large amount of measured data, including the CO concentration, air velocity, traffic speed, and traffic volume obtained from various sampling sites, 50 groups of experimental data were selected as statistical samples for each tunnel. The average CO emission factors could be calculated from statistical samples by using equation (1). As listed in Table 6 , there are differences in the average $\mathrm{CO}$ emission factors among the four urban tunnels. The average emission factors of Henglongshan Tunnel, Cejiexian Tunnel, Jiuweiling Tunnel, and Dameisha Tunnel were $1.075 \mathrm{~g} /(\mathrm{km} \cdot \mathrm{veh}), 1.245 \mathrm{~g} /(\mathrm{km} \cdot \mathrm{veh})$, $4.154 \mathrm{~g} /(\mathrm{km} \cdot \mathrm{veh})$, and $1.739 \mathrm{~g} /(\mathrm{km} \cdot \mathrm{veh})$, respectively. The average $\mathrm{CO}$ emission factor of the left bore of Jiuweiling Tunnel was the largest among the four tunnels, which was $4.416 \mathrm{~g} /(\mathrm{km} \cdot \mathrm{veh})$. The average CO emission factor of the right bore of Dameisha Tunnel was the smallest among the four tunnels, which was $0.713 \mathrm{~g} /(\mathrm{km} \cdot \mathrm{veh})$. Among the four tunnels, the $\mathrm{CO}$ emission factors derived from Jiuweiling 


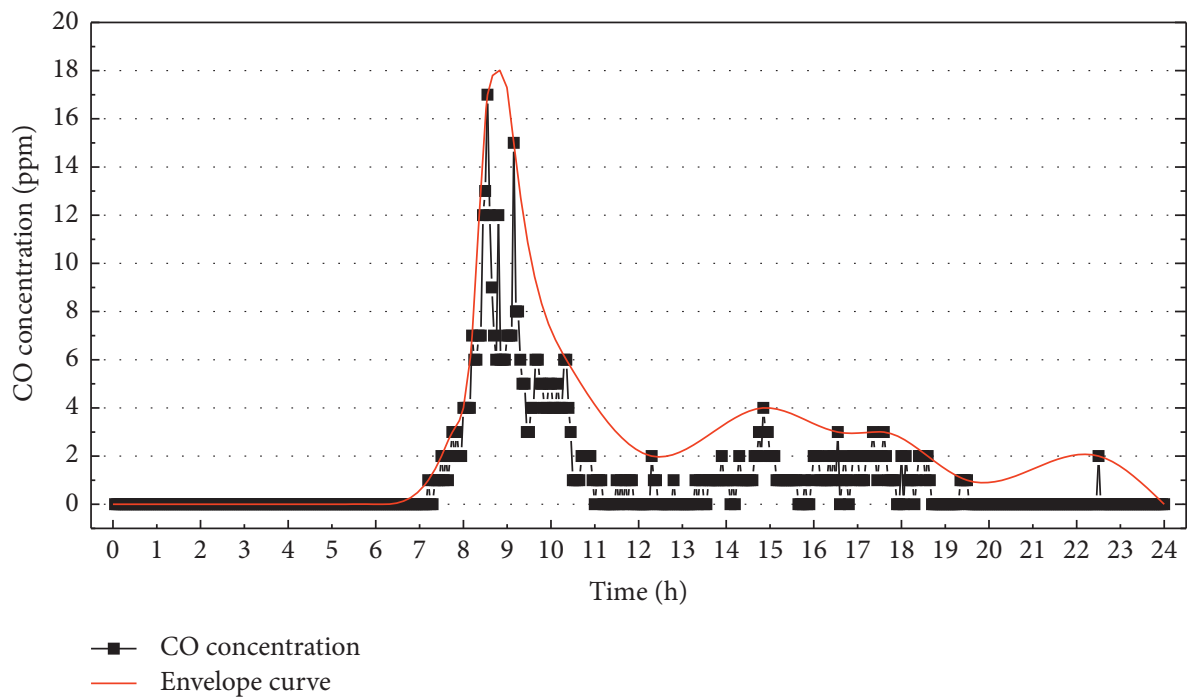

FIgURE 8: Diurnal profile of CO concentration in the left bore of Henglongshan Tunnel (ZK1+081).

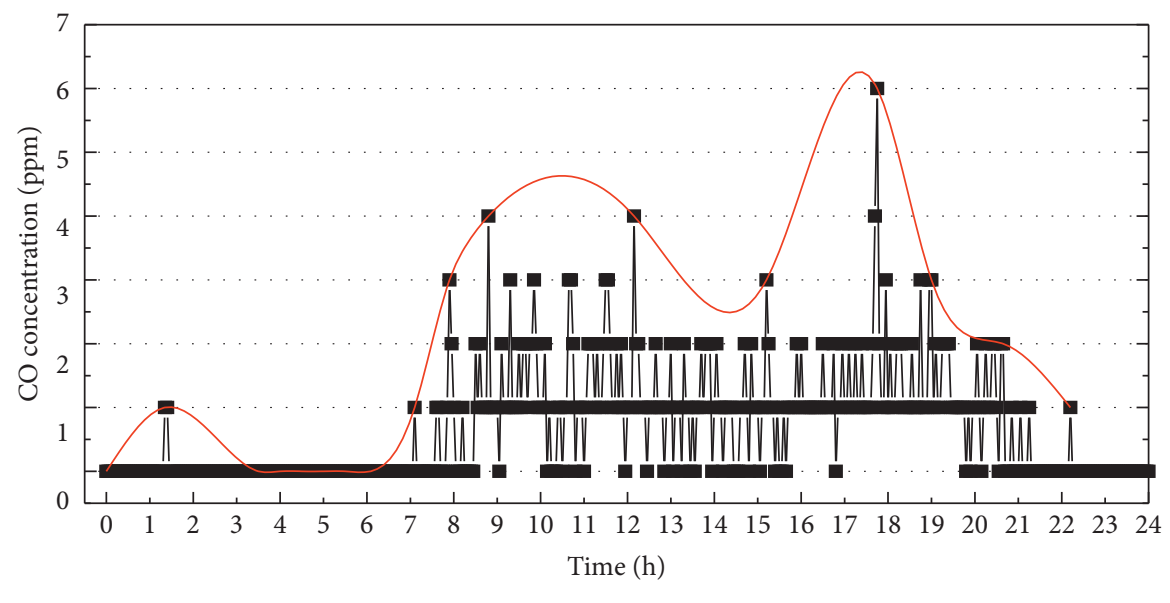

- $\mathrm{CO}$ concentration

- Envelope curve

FIgURE 9: Diurnal profile of CO concentration in the left bore of Dameisha Tunnel (ZK1+335).

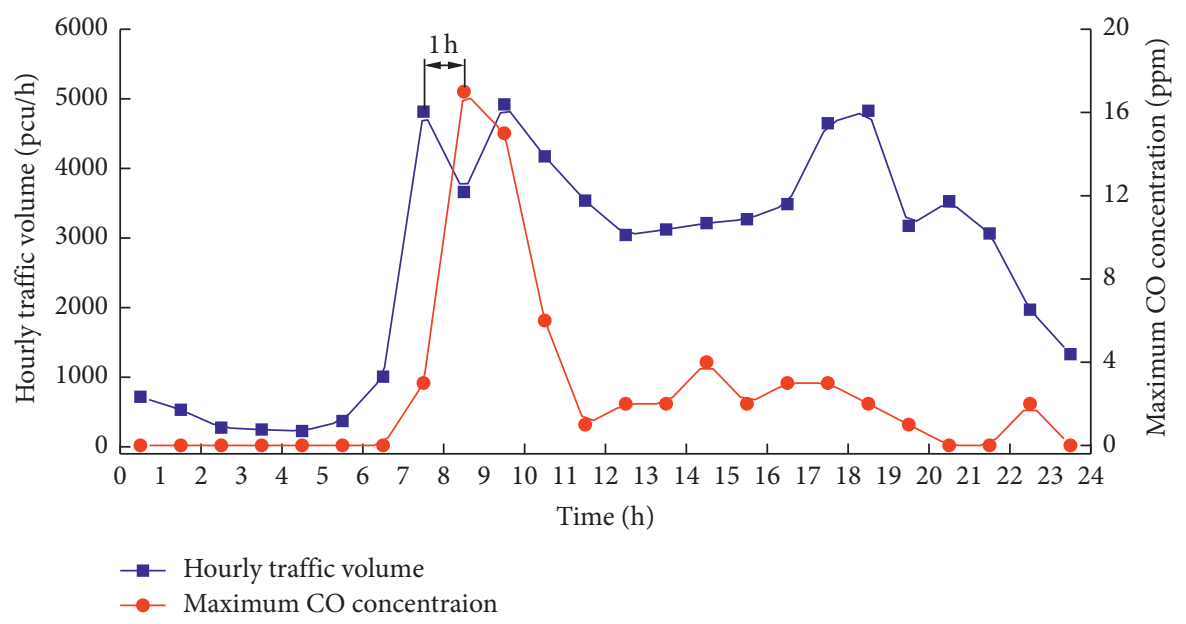

FIgURE 10: Relative variation of CO concentration and traffic flow in the left bore of Henglongshan Tunnel. 


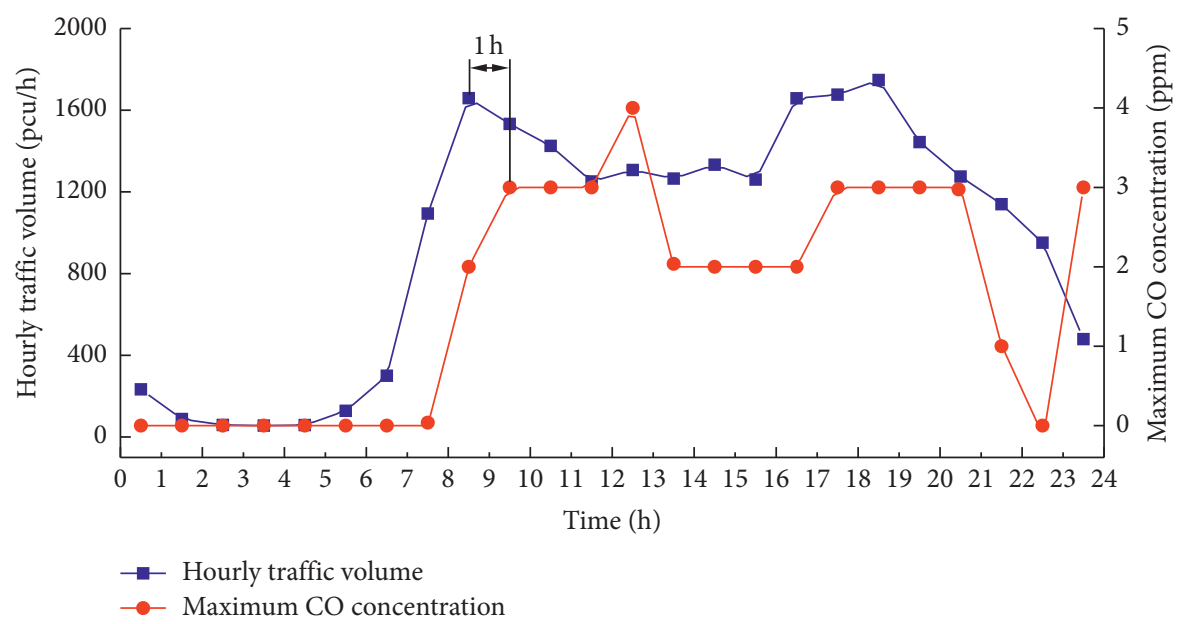

FIGURE 11: Relative variation of CO concentration and traffic flow in the left bore of Cejiexian Tunnel.

TABLE 5: Maximum CO concentrations and the corresponding measured data.

\begin{tabular}{|c|c|c|c|c|c|c|}
\hline Tunnel name & & $\begin{array}{c}\text { Maximum CO } \\
\text { concentration (ppm) }\end{array}$ & $\begin{array}{l}\text { Occurrence } \\
\text { time }\end{array}$ & $\begin{array}{l}\text { Hourly average air } \\
\text { velocity }(\mathrm{m} / \mathrm{s})\end{array}$ & $\begin{array}{c}\text { Hourly traffic } \\
\text { volume }(\mathrm{pcu} / \mathrm{h})\end{array}$ & $\begin{array}{l}\text { Average traffic } \\
\text { speed }(\mathrm{km} / \mathrm{h})\end{array}$ \\
\hline \multirow{2}{*}{$\begin{array}{l}\text { Henglongshan } \\
\text { Tunnel }\end{array}$} & $\begin{array}{l}\text { Left } \\
\text { bore }\end{array}$ & 17 & $8: 33$ & 2.8 & 3660 & 10 \\
\hline & $\begin{array}{l}\text { Right } \\
\text { bore }\end{array}$ & 9 & $11: 26$ & 2.9 & 4458 & 10 \\
\hline \multirow{2}{*}{ Cejiexian Tunnel } & $\begin{array}{l}\text { Left } \\
\text { bore }\end{array}$ & 7 & $19: 08$ & 1.5 & 1004 & 20 \\
\hline & $\begin{array}{l}\text { Right } \\
\text { bore }\end{array}$ & 6 & $16: 11$ & 2.6 & 1601 & 10 \\
\hline \multirow{2}{*}{ Jiuweiling Tunnel } & $\begin{array}{l}\text { Left } \\
\text { bore }\end{array}$ & 39 & $18: 25$ & 0.3 & 1774 & 10 \\
\hline & $\begin{array}{c}\text { Right } \\
\text { bore }\end{array}$ & 9 & $22: 21$ & 3.9 & 1801 & 30 \\
\hline \multirow{2}{*}{ Dameisha Tunnel } & $\begin{array}{l}\text { Left } \\
\text { bore }\end{array}$ & 6 & $17: 45$ & 4.9 & 2408 & 30 \\
\hline & $\begin{array}{l}\text { Right } \\
\text { bore }\end{array}$ & 8 & $11: 59$ & 3.8 & 2253 & 30 \\
\hline
\end{tabular}

Tunnel were 1.4 6.2 times that of the other three tunnels with large standard deviation. The calculation results of Henglongshan Tunnel and Cejiexian Tunnel were close to each other, whose $\mathrm{CO}$ emission factors were between 0.9 and $1.5 \mathrm{~g} /(\mathrm{km} \cdot \mathrm{veh})$. Except for the Dameisha Tunnel, the average emission factors were relatively close between the left and right holes of the other three tunnels, and there is a big gap on the average CO emission factors between the left and right holes of the Dameisha Tunnel, among which the average $\mathrm{CO}$ emission factor of the left hole was about 3.9 times that of the right hole.

Motor vehicle emissions are mainly affected by two kinds of factors: internal factors (motor vehicle itself) and external factors. The aforementioned characteristics of average $\mathrm{CO}$ emission factors were mainly caused by the differences of traffic volume and driving speed in the four tunnels. The traffic volume and traffic environment of the four tunnels were different from each other, resulting in the differences of traffic speed in the tunnels. The $\mathrm{CO}$ emission factor is a function of traffic speed and road gradient. Different speeds make different emission factors. Deng and Liao et al. pointed out that the vehicle $\mathrm{CO}$ emission factor showed the parabolic changes with the increase of vehicle speed and fell to the lowest level when the speed increased to $60 \mathrm{~km} / \mathrm{h}$ $[41,42]$. There were one or more orders of magnitude differences between idle-speed condition and high-speed condition. Tunnel measurement showed that the average daily traffic volumes of the left bore and right bore of Henglongshan Tunnel were 64,314 pcu/d and 71,535 pcu/d, respectively. The average daily traffic volumes of the left bore and right bore of Dameisha Tunnel during the nonofficial holiday period were $38,094 \mathrm{pcu} / \mathrm{d}$ and $37,054 \mathrm{pcu} / \mathrm{d}$, respectively, accounting for $59 \%$ and $52 \%$ of those of Henglongshan Tunnel. The smaller traffic flow made the vehicle speed higher. The traffic speed in Dameisha Tunnel usually remained between $30 \mathrm{~km} / \mathrm{h}$ and $60 \mathrm{~km} / \mathrm{h}$, rarely showing the speed lower than $30 \mathrm{~km} / \mathrm{h}$ or blocked condition. Thus, the vehicle CO emission factors in Dameisha Tunnel were relatively small. 


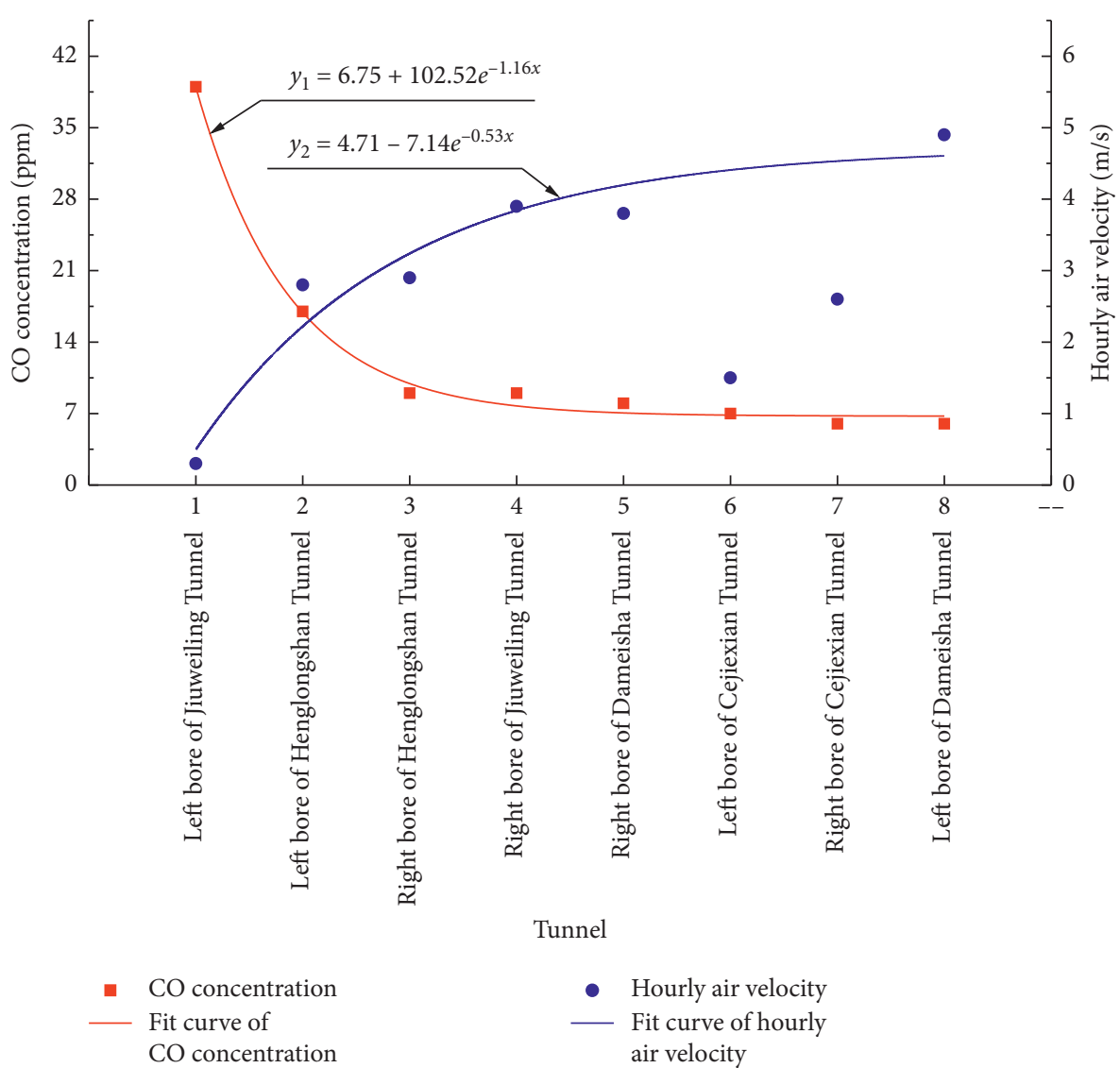

FIgURE 12: Relationship between maximum CO concentration and hourly air velocity.

TABLE 6: Average vehicle CO emission factors (unit: $\mathrm{g} /(\mathrm{km} \cdot \mathrm{veh})$.

\begin{tabular}{lcccccccc}
\hline \multirow{2}{*}{ Category } & \multicolumn{2}{c}{ Henglongshan Tunnel } & \multicolumn{2}{c}{ Cejiexian Tunnel } & \multicolumn{2}{c}{ Jiuweiling Tunnel } & \multicolumn{2}{c}{ Dameisha Tunnel } \\
& Left bore & Right bore & Left bore & Right bore & Left bore & Right bore & Left bore & Right bore \\
\hline Average & 1.241 & 0.909 & 1.022 & 1.467 & 4.416 & 3.892 & 2.765 \\
Standard deviation & 0.512 & 0.277 & 0.650 & 0.468 & 1.348 & 1.264 & 1.239 \\
Minimum & 0.515 & 0.474 & 0.680 & 0.874 & 2.357 & 2.527 & 1.166 \\
Maximum & 2.954 & 1.951 & 4.190 & 2.831 & 8.072 & 9.268 & 6.531 & 0.309 \\
Sample number (group) & 50 & 50 & 50 & 50 & 50 & 50 & 50 & 28 \\
\hline
\end{tabular}

The average daily traffic volumes of the left bore and right bore of Jiuweiling Tunnel were 32,753 pcu/d and 37,641 pcu/ $\mathrm{d}$, respectively, and close to those of Dameisha Tunnel. However, a junction and a traffic light were located at the south outlet of the tunnel about $300 \mathrm{~m}$, so the vehicles had to queue up to pass through the tunnel and the traffic light during rush hours. Traffic jams often lasted for more than an hour with full length congested in the tunnel, and vehicle speed was all below $30 \mathrm{~km} / \mathrm{h}$. Under the low-speed condition or idle condition, the incomplete fuel combustion brought about a sharp rise in the vehicle $\mathrm{CO}$ emission factor. Therefore, the calculation results of vehicle $\mathrm{CO}$ emission factors in Jiuweiling Tunnel were relatively high.

3.2.2. Comparison of CO Emission Factors. Based on the field measurement in the four typical tunnels in Shenzhen, the average $\mathrm{CO}$ emission factors of mixed traffic were obtained by means of theoretical analysis and calculation, and they could represent vehicle emission level in Shenzhen in 2014. Table 7 lists the research results of vehicle CO emission factors in different regions and years. Due to the influence of many factors, such as the operating condition, test year, traffic composition, automotive emission standards, and fuel quality, the vehicle $\mathrm{CO}$ emission factors show significant differences among different years and present a decreasing trend and characteristic. Compared with Hong Kong and Taiwan in China, it is found that the average CO emission factors from motor vehicles in Shenzhen in 2014 are similar to those of Hong Kong Shing Mun Tunnel and Taipei tunnel in 2000 2003. Higher economic and technological level, more advanced automobile engine technology and exhaust control technology, and earlier introduction of Western emission regulations make vehicle emission factors in Hong Kong and Taiwan far less than those of the mainland and close to the level of 
TABle 7: Average CO emission factors of motor vehicles (mixed traffic) in different regions of China.

\begin{tabular}{|c|c|c|c|c|c|c|}
\hline Tunnel/test method & City & Test year & $\begin{array}{l}\text { Traffic speed } \\
(\mathrm{km} / \mathrm{h})\end{array}$ & $\begin{array}{c}\mathrm{EF} \\
(\mathrm{g} /(\mathrm{km} \cdot \mathrm{veh}))\end{array}$ & Test condition & Reference \\
\hline Xi'an North Road Tunnel & Xi'an & 1996 & $40 \sim 60$ & 33.279 & Urban road tunnel & {$[43]$} \\
\hline Tanyugou tunnel & Beijing & 1999 & $10 \sim 70$ & 23.467 & Urban road tunnel & {$[44]$} \\
\hline Bench test & Beijing & 2000 & 19.98 & 26.100 & Urban comprehensive condition & {$[45]$} \\
\hline Taipei tunnel & Taipei & 2000 & $60-70$ & 3.64 & Urban road tunnel & {$[46]$} \\
\hline Road calculation model & Shanghai & 2003 & 26.9524 & 31.4395 & Urban hypo-artery road & {$[47]$} \\
\hline Shing Mun Tunnel & Hong Kong & 2003 & $60 \sim 70$ & 1.845 & Urban road tunnel & {$[48]$} \\
\hline Bench test & Ningbo & 2005 & $20 \sim 30$ & 21.220 & Ningbo road condition & [49] \\
\hline Tunnel measurement & Xi'an & 2006 & 43.3 & 6.89 & Urban road tunnel & {$[50]$} \\
\hline Road calculation model & Beijing & 2010 & - & 3.75 & Urban arterial road & {$[51]$} \\
\hline Yingpan road tunnel & Changsha & 2013 & 30 & 3.22 & Urban road tunnel & {$[30]$} \\
\hline Wenchang Gate-Peace Gate Tunnel & Xi'an & 2014 & $40 \sim 60$ & 1.097 & Urban road tunnel & {$[52]$} \\
\hline Henglongshan Tunnel & & & $10 \sim 40$ & 1.075 & & \\
\hline Jiuweiling Tunnel & Shenzhen & 2014 & $10 \sim 40$ & 4.154 & Urban road tunnel & \\
\hline Cejiexian Tunnel & Shenzhen & 2014 & $10 \sim 40$ & 1.245 & Urban road tunnel & This study \\
\hline Dameisha Tunnel & & & $30 \sim 60$ & 2.028 & & \\
\hline Wenchang Gate-Peace Gate Tunnel & Xi'an & 2015 & 33.18 & 1.097 & Urban road tunnel & {$[53]$} \\
\hline East Yan'an Road Tunnel & Shanghai & 2016 & 33.5 & 1.84 & Urban road tunnel & {$[54]$} \\
\hline
\end{tabular}

developed countries [55, 56]. Compared with the other regions of the Chinese mainland, the average vehicle $\mathrm{CO}$ emission factors in Shenzhen in 2014 are of the same order of magnitude compared with other research results after 2006, while they are one order of magnitude smaller than those before 2006. 2006 can be regarded as an important dividing point of vehicle $\mathrm{CO}$ emission factors. From 2001 to 2005, China began to implement the emission standard "China I" of motor vehicles for the first time nationwide, which means that the vehicle exhaust emission before 2001 was unlimited. Before 2006, the new cars produced and put into use according to the emission standard "China I" accounted for only a part of the vehicle ownership at that time. Therefore, the average $\mathrm{CO}$ emission factors of motor vehicles were all beyond $20 \mathrm{~g} /(\mathrm{km} \cdot \mathrm{veh})$ before 2006, far greater than the "China I" emission limit of $2.72 \mathrm{~g} / \mathrm{km}$. With the implementation of the "China II" emission standard and continuous fleet renewal, the average $\mathrm{CO}$ emission factors of motor vehicles decreased sharply after 2006 , and they were one order of magnitude smaller than those before 2006 .

3.2.3. Total CO Emissions from Vehicles. As the average CO emission factor of motor vehicles in Dameisha Tunnel is close to the average level of the four tunnels and considering that the traffic operation condition of the whole city is better than that of the tunnel, it is considered that the vehicle CO emission factor derived from the Dameisha Tunnel could represent the average emission level of motor vehicles in Shenzhen in 2014 and be used to estimate the total $\mathrm{CO}$ emissions of motor vehicles in the whole year. According to the Shenzhen Statistical Yearbook, the vehicle population of Shenzhen reached $3,153,902$ by the end of 2014, ranking 4th in China [57]. Without directly available data, the average annual vehicle kilometers traveled in Shenzhen referred to those of Guangzhou [42]. The two cities are adjacent to each other in the Pearl River Delta region, and the automobile technology level is consistent with each other. Therefore, it is considered that there are no significant differences in vehicle mileage. The annual vehicle kilometers traveled in Guangzhou are listed in Table 8. The fleet composition is determined according to the measurement results in this study and the statistical data of motor vehicles in Shenzhen in 2014 [57, 58]. And the weight mean of average annual vehicle mileage was $27,440 \mathrm{~km} /$ year in 2014 , calculated by using equation (2).

According to the average vehicle $\mathrm{CO}$ emission factor, the vehicle population, and average annual vehicle mileage data, the total vehicle $\mathrm{CO}$ emissions in urban areas of Shenzhen in 2014 could be estimated by equation (3):

$$
Q_{\mathrm{CO}}=3153902 \times 27440 \times 2.028 \times 10^{-6}=175509 t .
$$

The calculation result shows that the total $\mathrm{CO}$ emissions from motor vehicles reached 175,509 tons throughout the year 2014 in Shenzhen, resulting in a huge threat to the urban environment. Wang pointed out that motor vehicles contributed $91 \%$ for the total $\mathrm{CO}$ emissions in urban areas of Shenzhen [59]. Both the huge motor vehicle CO emissions and the high contribution rate indicated that vehicle exhaust pollution had become the main source of urban air pollution.

\subsection{Annual Reduction Rate of CO Emission Factors.} Figure 13 indicates the development process of vehicle emission factors and emission regulations in China in the recent past 20 years. It can be seen from Figure 13 that, with the great progress of automobile engine technology and exhaust control technology, the successive implementations of stricter national vehicle emission regulations, and the continuous improvement of fuel quality, the vehicle $\mathrm{CO}$ emission factors decreased year by year and presented a first fast and then slow-down change trend. Vehicle CO emission factors have also gradually shrunk from far exceeding the vehicle emission limit to 
TABLE 8: Annual vehicle kilometers traveled.

\begin{tabular}{lccccccc}
\hline Traffic fleet & Passenger car & Taxi & Bus & Coach & Light-duty truck & Heavy-duty truck & Motorcycle \\
\hline AVKT (km/year) & 24,719 & 145,894 & 71,947 & 164,962 & 24,748 & 27,593 & 4331 \\
Traffic composition (\%) & 85.42 & 0.52 & 0.99 & 1.11 & 7.99 & 3.76 & 0.21 \\
\hline
\end{tabular}

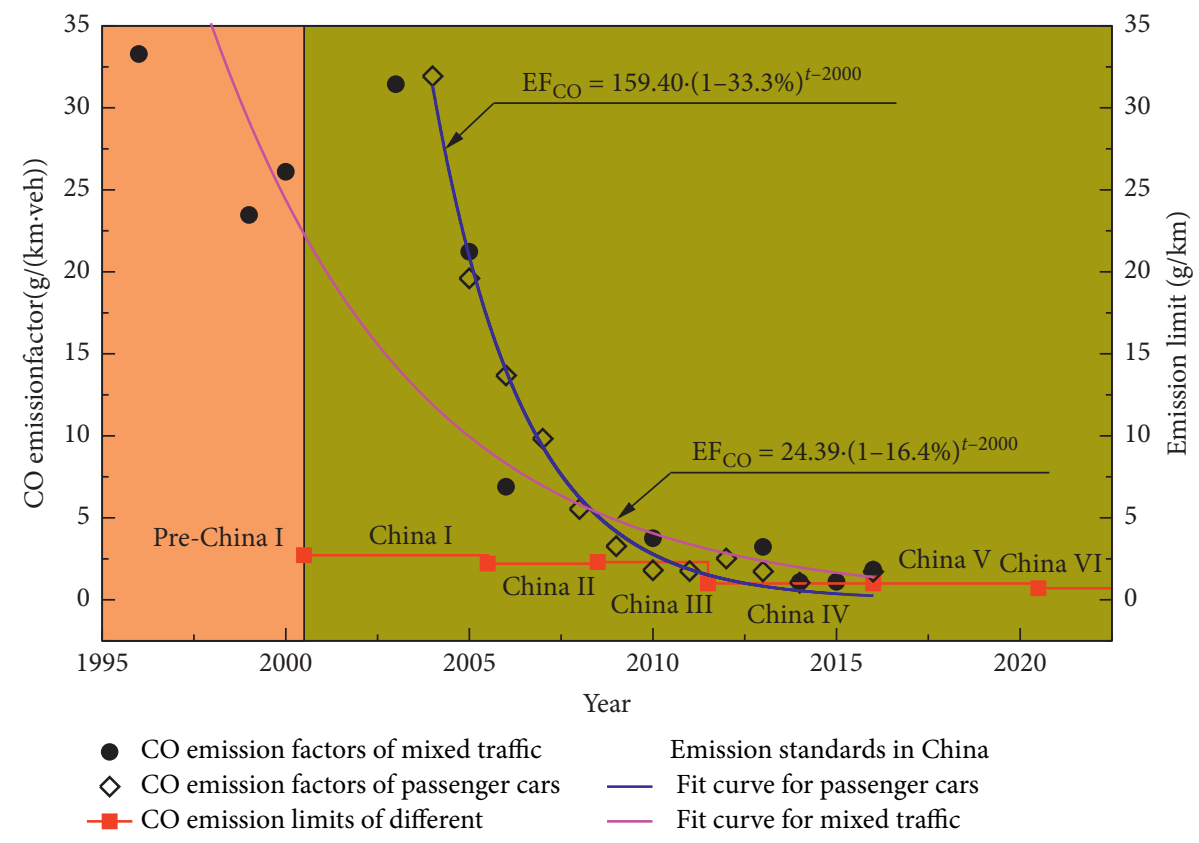

Figure 13: Changes in $\mathrm{CO}$ emission factors.

approaching it. In order to quantitatively evaluate the development and improvement process of vehicle emission factors, the following fitting functions are established with reference to equation (4) for nonlinear fitting of vehicle emission factors:

$$
A \cdot(1-\omega)^{x-2000}=y \text {, }
$$

where $A$ and $\omega$ are coefficients of the function and 2000 is a constant term, which is the base year with reference to the current specification.

The fitting functions of $\mathrm{CO}$ emission factor distribution for mixed traffic and passenger cars are $\mathrm{EF}_{\mathrm{MX}}=24.39 \cdot(1-16.4 \%)^{x-2000}$ and $\mathrm{EF}_{\mathrm{PC}}=159.40 \cdot(1-33.3 \%)^{x-2000}$, respectively. Correspondingly, the fitted annual reduction rates of the $\mathrm{CO}$ emission factors for passenger cars and mixed traffic are $16.4 \%$ and $33.3 \%$, respectively, which are 8 and 17 times of the $2 \%$ stipulated in the current specification. Furthermore, based on the gap between the maximum and minimum values of statistical data, the annual reduction rate of vehicle $\mathrm{CO}$ emission factors can also be calculated by using equation (5). When ignoring obvious regional differences in the same period in China, the $\mathrm{CO}$ emission factors of mixed traffic, from $33.279 \mathrm{~g} /(\mathrm{km} \cdot \mathrm{veh})$ tested in Xi'an North Road Tunnel in 1996 to $1.075 \mathrm{~g} /(\mathrm{km} \cdot \mathrm{veh})$ tested in Shenzhen Henglongshan Tunnel in 2014, decreased by $96.8 \%$ over a span of 18 years and reduced by $17.4 \%$ per year on average. The emission factors of passenger cars (Table 9) reduced by
96.7\% over the past decade from 2004 to 2014 and by $29.0 \%$ annually on average. The numerical calculation indicates the annual reduction rates of the $\mathrm{CO}$ emission factors for mixed traffic and passenger cars are $17.4 \%$ and $29.0 \%$, respectively, which are 9 and 15 times of the current in-use annual reduction rate of $2 \%$. The reduction results obtained by the above two methods are pretty close, and the annual reduction rates from numerical calculation are a subset of the fitting results and within the fitting range. Thus, it could effectively reduce vehicle $\mathrm{CO}$ emission factors in the aspects of increasing investment on the research of automobile engine technology and exhaust control technology, promoting higher quality fuel and stricter emission regulations, accelerating elimination of "yellow label cars" (heavy-polluting vehicles), and taking effective measures to improve road traffic conditions. Based on the comprehensive consideration of unbalanced economic and technological development among cities in China, it is necessary to consider the safety factor (approximately 20\%) for the reduction results from fitting regression and numerical calculation with reference to the current ventilation specification [13]. Therefore, the annual reduction rate of CO base emissions can be optimized from the intersection set of the two results obtained by two different methods, which ranges from $3.5 \%$ to $5.8 \%$, and the conservative value of $4 \%$ may be more reasonable for ventilation calculation. 
TABLE 9: CO emission factors of passenger cars in different cities in China.

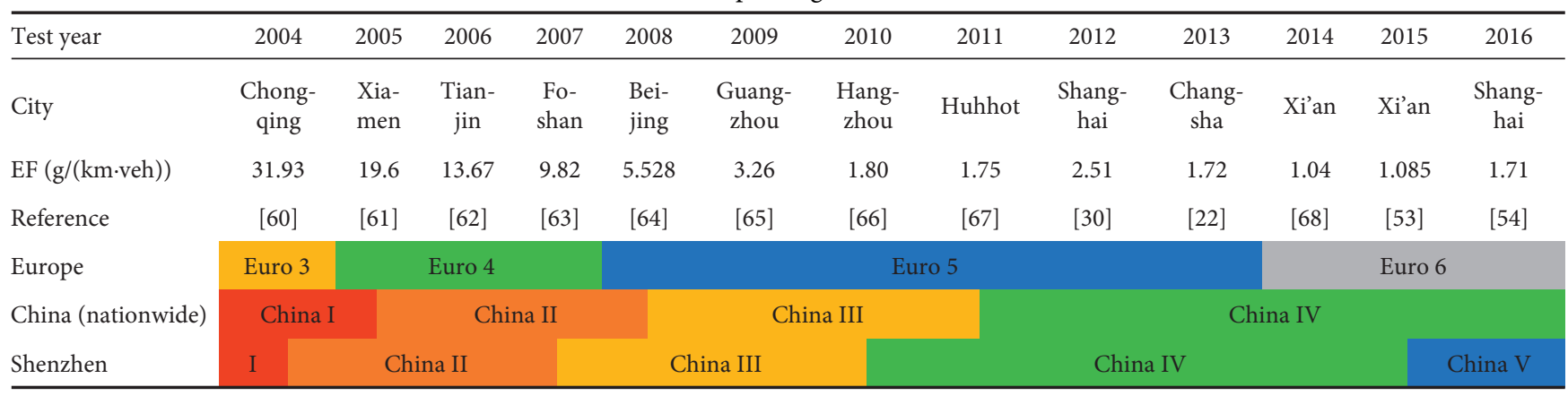

\section{Conclusions}

In this study, a detailed monitoring investigation was conducted in four tunnels, Henglongshan Tunnel, Cejiexian Tunnel, Jiuweiling Tunnel, and Dameisha Tunnel in Shenzhen, China, for collecting data on the traffic flow, air velocity, and CO concentration. Based on the measured data, the average $\mathrm{CO}$ emission factors and annual reduction rate were obtained by calculation and comparison. The main conclusions are as follows:

(1) The traffic flow of the four tunnels had been approaching the design values of traffic capacity, or even beyond the limits. Passenger cars accounted for $75 \% \sim 81 \%$ of the total traffic, and the proportion of gasoline vehicles varied from $68 \%$ to $75 \%$.

(2) The average daily air velocities of the four tunnels were all within $5 \mathrm{~m} / \mathrm{s}$, and the maximum air velocities were beyond the limit of $10 \mathrm{~m} / \mathrm{s}$, the largest of which peaked at $11 \mathrm{~m} / \mathrm{s}$. Diurnal variation curves of air velocity in the four tunnels had a larger fluctuation with time, except for the left bore of Jiuweiling Tunnel.

(3) The maximum CO concentrations of Henglongshan Tunnel, Cejiexian Tunnel, Jiuweiling Tunnel, and Dameisha Tunnel were $17 \mathrm{ppm}, 7 \mathrm{ppm}, 39 \mathrm{ppm}$, and $8 \mathrm{ppm}$, respectively. The $\mathrm{CO}$ concentration level was far less than the admissible value.

(4) The average CO emission factors of Henglongshan Tunnel, Cejiexian Tunnel, Jiuweiling Tunnel, and Dameisha Tunnel were $1.075 \mathrm{~g} /(\mathrm{km} \cdot \mathrm{veh}), 1.245$ $\mathrm{g} /(\mathrm{km} \cdot \mathrm{veh}), 4.154 \mathrm{~g} /(\mathrm{km} \cdot \mathrm{veh})$, and $1.739 \mathrm{~g} /(\mathrm{km} \cdot \mathrm{veh})$, respectively. The annual reduction rate of $\mathrm{CO}$ emission factors for mixed traffic and passenger cars is $16.4 \%$ and $33.3 \%$, respectively, by fitting regression and $17.4 \%$ and $29.0 \%$, respectively, by extremum calculation. When considering the safety factor of $20 \%$ with reference to the current ventilation specification in China, it is more reasonable for CO base emission to adopt $4 \%$ as an optimized annual reduction rate for ventilation design in urban tunnels.

Tunnel ventilation system is the key to ensure safe and high-effective operation of urban road tunnels. However, due to the continuous decline in $\mathrm{CO}$ emission factors and unreasonable calculation parameters in ventilation design, the overdesign problem of the ventilation system is becoming increasingly prominent. The results of this paper can effectively reduce energy waste, promote the sustainable development of urban tunnels, and provide data support and reference for the ventilation design of other tunnel projects. On the basis of the results of the previous studies, the research team will further study the pollutant emission factors, reasonable ventilation design parameters, and ventilation control indexes and further expand the research samples.

\section{Data Availability}

The data used to support the findings of this study are presented in the tables and figures.

\section{Conflicts of Interest}

The authors declare that they have no conflicts of interest.

\section{Acknowledgments}

The authors would like to acknowledge the financial support provided by the National Key R\&D Program of China (Grant no. 2018YFB1600100), the National Natural Science Foundation of China (Grant nos. 51978065 and 51678063), the China Postdoctoral Science Foundation (Grant no. 2016M602738), and the Chang Jiang Scholars Program (Grant no. Q2018209). The authors thank the "Transport and Management Bureau of Shenzhen Municipality" for assistance with the experiments.

\section{References}

[1] J. Chen, W. Liu, L. Chen et al., "Failure mechanisms and modes of tunnels in monoclinic and soft-hard interbedded rocks: a case study," KSCE Journal of Civil Engineering, vol. 24, no. 4, pp. 1357-1373, 2020.

[2] L. P. Li, S. Q. Sun, J. Wang, W. M. Yang, S. G. Song, and Z. D. Fang, "Experimental study of the precursor information of the water inrush in shield tunnels due to the proximity of a water-filled cave," International Journal of Rock Mechanics and Mining Sciences, vol. 130, pp. 1-12, 2020. 
[3] W. Liu, J. Chen, L. Chen, Y. Luo, Z. Shi, and Y. Wu, "Nonlinear deformation behaviors and a new approach for the classification and prediction of large deformation in tunnel construction stage: a case study," European Journal of Environmental and Civil Engineering, pp. 1-29, 2020.

[4] Y. Luo, J. Chen, Z. Shi et al., "Mechanical and deformation characteristics and optimization of support parameters for superlarge-span tunnel: a case study from laohushan tunnel," Advances in Civil Engineering, vol. 2020, pp. 1-17, 2020.

[5] M. J. Zhang, S. H. Li, and P. F. Li, "Numerical analysis of ground displacement and segmental stress and influence of yaw excavation loadings for a curved shield tunnel," Computers and Geotechnics, vol. 118, pp. 1-12, 2020.

[6] Y. Luo and J. Chen, "Research status and progress of tunnel frost damage," Journal of Traffic and Transportation Engineering (English Edition), vol. 6, no. 3, pp. 297-309, 2019.

[7] P. Li, C. Feng, H. Liu, Y. Zhao, Z. Li, and H. Xiong, "Development and assessment of a water pressure reduction system for lining invert of underwater tunnels," Marine Georesources \& Geotechnology, pp. 1-7, 2019.

[8] P. F. Li, K. Y. Chen, F. Wang, and Z. Li, "An upper-bound analytical model of blow-out for a shallow tunnel in sand considering the partial failure within the face," Tunnelling and Underground Space Technology, vol. 91, pp. 1-12, 2019.

[9] P. F. Li, H. H. Zou, F. Wang, and H. C. Xiong, "An analytical mechanism of limit support pressure on cutting face for deep tunnels in the sand," Computers and Geotechnics, vol. 119, pp. 1-9, 2020.

[10] J. Lai, X. Wang, J. Qiu et al., "A state-of-the-art review of sustainable energy based freeze proof technology for coldregion tunnels in China," Renewable and Sustainable Energy Reviews, vol. 82, no. 3, pp. 3554-3569, 2018.

[11] Y. B. Luo, J. X. Chen, S. T. Gao, X. H. Deng, and P. S. Diao, "Stability analysis of super-large-section tunnel in loess ground considering water infiltration caused by irrigation," Environmental Earth Sciences, vol. 76, no. 22, pp. 1-17, 2017.

[12] Ministry of Ecology and Environment of the People's Republic of China, China Mobile Source Environmental Management Annual Report, 2019.

[13] China Communications Press, Ministry of Transport of the People's Republic of China, Guidelines for Design of Ventilation of Highway Tunnels, China Communications Press, Beijing, China, 2014.

[14] W. A. Lonneman, R. L. Seila, and S. A. Meeks, "Non-methane organic composition in the lincoln tunnel," Environmental Science \& Technology, vol. 20, no. 8, pp. 790-796, 1986.

[15] L. Y. Chan, L. Zeng, Y. Qin, and S. C. Lee, "CO concentration inside the cross harbor tunnel in Hong Kong," Environment International, vol. 22, no. 4, pp. 405-409, 1996.

[16] L. Y. Chan, Y. M. Liu, S. C. Lee, and C. Y. Chan, "Carbon monoxide levels measured in major commuting corridors covering different land use and roadway microenvironments in Hong Kong," Atmospheric Environment, vol. 36, no. 2, pp. 255-264, 2002.

[17] W. K. Chow and M. Y. Chan, "Field measurement on transient carbon monoxide levels in vehicular tunnels," Building and Environment, vol. 38, no. 2, pp. 227-236, 2003.

[18] A. Kristensson, C. Johansson, R. Westerholm et al., "Real-world traffic emission factors of gases and particles measured in a road tunnel in Stockholm, Sweden," Atmospheric Environment, Atmospheric Environment, vol. 38, no. 5, pp. 657-673, 2004.

[19] C. M. Ma, G. B. Hong, and C. T. Chang, "Influence of traffic flow patterns on air quality inside the longest tunnel in Asia,"
Aerosol and Air Quality Research, vol. 11, no. 1, pp. 44-50, 2011.

[20] H.-C. Li, K.-S. Chen, C.-H. Lai, and H.-K. Wang, "Measurements of gaseous pollutant concentrations in the hsuehshan traffic tunnel of northern Taiwan," Aerosol and Air Quality Research, vol. 11, no. 6, pp. 776-782, 2011.

[21] R. Zhou, S. S. Wang, C. Z. Shi et al., "Study on the traffic air pollution inside and outside a road tunnel in Shanghai, China," PLoS One, vol. 9, no. 11, pp. 1-9, 2014.

[22] Q. Li, C. Chen, Y. Deng et al., "Influence of traffic force on pollutant dispersion of $\mathrm{CO}, \mathrm{NO}$ and particle matter (PM2.5) measured in an urban tunnel in Changsha, China," Tunnelling and Underground Space Technology, vol. 49, pp. 400-407, 2015.

[23] PIARC-World Road Association, PIARC Technical Committee on Road Tunnels Operation, Road Tunnels: Vehicle Emissions and Air Demand for Ventilation, France, PIARCWorld Road Association, Paris, France, 2012.

[24] PIARC-World Road Association, PIARC Technical Committee on Road Tunnels Operation, Road Tunnels: Vehicle Emissions and Air Demand for Ventilation, PIARC-World Road Association, Paris, France, 2019.

[25] Y. X. Yang, X. L. Cai, Q. Du, C. W. Liu, J. Liu, and Z. G. Jin, "Research on the real road emission factors and fuel consumption of typical vehicles on the roads," Journal of Combustion Science and Technology, vol. 9, no. 2, pp. 112-118, 2003.

[26] Z. L. Yao, Y. L. Ma, K. B. He, H. Huo, and T. Guo, “A study on the real-world vehicle emission characteristics in Ningbo," Acta Scientiae Circumstantiae, vol. 26, no. 8, pp. 1229-1234, 2006.

[27] L. Q. He, J. H. Song, J. N. Hu, S. X. Xie, and L. Zu, "an investigation of the $\mathrm{CH}_{4}$ and $\mathrm{N}_{2} \mathrm{O}$ emission factors of lightduty gasoline vehicles," Environmental Science, vol. 35, no. 12, pp. 4489-4494, 2014.

[28] K. F. Ho, S. C. Lee, W. K. Ho et al., "Vehicular emission of volatile organic compounds (VOCs) from a tunnel study in Hong Kong," Atmospheric Chemistry \& Physics, vol. 9, no. 9, pp. 7491-7504, 2009.

[29] J. F. Liu and J. P. Gao, "Analysis of CO emissions and its control technology of mountain urban tunnel," Transportation Science \& Technology, vol. 6, pp. 72-75, 2013.

[30] Y. Deng, C. Chen, Q. Li et al., "Measurements of real-world vehicle $\mathrm{CO}$ and NOx fleet average emissions in urban tunnels of two cities in China," Atmospheric Environment, vol. 122, pp. 417-426, 2015.

[31] X. Y. Song and S. D. Xie, "Development of vehicular emission inventory in China," Environmental Science, vol. 27, no. 6, pp. 1041-1045, 2006.

[32] H. Cai and S. Xie, "Estimation of vehicular emission inventories in China from 1980 to 2005," Atmospheric Environment, vol. 41, no. 39, pp. 8963-8979, 2007.

[33] J. Lang, S. Cheng, Y. Zhou, Y. Zhang, and G. Wang, "Air pollutant emissions from on-road vehicles in China, 1999-2011," Science of the Total Environment, vol. 496, pp. 1-10, 2014.

[34] L. X. Fu, K. B. He, D. Q. He, Z. Z. Tang, and J. M. Hao, “A study on models of mobile source emission factor," Acta Scientiae Circumstantiae, vol. 17, no. 4, pp. 474-479, 1997.

[35] D. Q. He, J. M. Hao, K. B. He, and L. X. Fu, "Vehicle emission factors determination using model calculation," Environmental Science, vol. 19, no. 3, pp. 7-10, 1998. 
[36] S. D. Xie, X. Y. Song, and X. H. Shen, "Calculating vehicular emission factors with COPERT III mode in China," Environmental Science, vol. 27, no. 3, pp. 415-419, 2006.

[37] China Communications Press, Ministry of Communications of the People's Republic of China, Specifications for Design of Ventilation and Lighting of Highway Tunnel, China Communications Press, Beijing, China, 2000.

[38] S. C. Wang, H. X. Liu, and H. W. Wang, "Experiment study based on vehicle $\mathrm{CO}$ criterion emission amount in highway tunnel," Journal of Highway and Transportation Research and Development, vol. 21, no. 9, pp. 153-157, 2004.

[39] C. Guo, M. N. Wang, Y. W. Li, S. Z. Tian, and R. Q. Zhou, "Research on discount rate of $\mathrm{CO}$ and smoke baseline emission in road tunnel ventilation," Journal of Highway and Transportation Research and Development, vol. 25, no. 10, pp. 105-109, 2008.

[40] Y. B. Luo, J. X. Chen, W. W. Liu et al., "The energy-saving of urban tunnel ventilation based on the investigation of the annual discount rate of co baseline emission in city of Shenzhen," Journal of Testing and Evaluation, vol. 47, no. 4, pp. 3041-3058, 2019.

[41] S. X. Deng, Analysis Method of the Effects of Air Pollution for Long Highway Tunnel, Science Press, Beijing, China, 2004.

[42] H. B. Liao, Z. Yu, B. Zhou et al., "Characteristics of motor vehicle exhaust emission in Guangzhou," Environmental Science \& Technology, vol. 35, no. 1, pp. 134-138, 2012.

[43] S. X. Deng, P. Cheng, and W. Zhu, "Vehicular emission factors of CO, THC and NOx from freeway tunnel," Research of Environmental Sciences, vol. 13, no. 2, pp. 32-35, 2000.

[44] W. Wang, H. H. Ye, Y. H. Li, H. J. Liu, and M. Y. Wang, "Study on emission factors of $\mathrm{CO}, \mathrm{SO}_{2}$ and $\mathrm{NOx}$ in Tanyugou highway tunnel," Research of Environmental Sciences, vol. 14, no. 4, pp. 5-8, 2001.

[45] Z. X. Zhou, Y. Yuan, X. L. Liu et al., "The study of driving cycle and emission factor of vehicle in Beijing city," Acta Scientiae Circumstantiae, vol. 20, no. 1, pp. 48-53, 2000.

[46] M.-Y. Hwa, C.-C. Hsieh, T.-C. Wu, and L.-F. W. Chang, "Real-world vehicle emissions and VOCs profile in the Taipei tunnel located at Taiwan Taipei area," Atmospheric Environment, vol. 36, no. 12, pp. 1993-2002, 2002.

[47] X. F. Su, B. Q. Fan, Y. D. Huang, and J. J. Liu, "Emission factors of pollutions from motor vehicles on hypo-artery in urban road net," Journal of University of Shanghai for Science and Technology, vol. 26, no. 4, pp. 318-322, 2004.

[48] Y. Cheng, S. C. Lee, K. F. Ho, and P. K. K. Louie, "On-road particulate matter (PM2.5) and gaseous emissions in the Shing Mun tunnel, Hong Kong," Atmospheric Environment, vol. 40, no. 23, pp. 4235-4245, 2006.

[49] X. K. Tu, C. Z. Li, and F. Z. Li, “The vehicle synthesis emissions factor of urban road in Ningbo urban area," Research of Environmental Sciences, vol. 21, no. 2, pp. 95-98, 2008.

[50] W. B. Song, "Study on vehicle emission pollution and pollution control countermeasures in Xi'an," Thesis, Xi'an University of Architecture and Technology, Xi'an, China, 2008.

[51] R. K. Li, T. Zhao, Z. P. Li et al., "Estimation of average traffic emission factor based on synchronized incremental traffic flow and air pollutant concentration," Environmental Science, vol. 35, no. 4, pp. 1245-1249, 2014.

[52] P. S. Tian, J. J. Cao, Y. M. Han, N. N. Zhang, and Y. Q. Zhou, "A tunnel test for emission factors of motor vehicles in Xi'an," Science \& Technology Review, vol. 33, no. 6, pp. 59-63, 2015.

[53] D. Zhao, H. Chen, H. Shao, and X. Sun, "Vehicle emission factors for particulate and gaseous pollutants in an urban tunnel in Xi'an, China," Journal of Chemistry, vol. 2018, Article ID 8964852, 11 pages, 2018.

[54] C. Huang, S. Tao, S. Lou et al., "Evaluation of emission factors for light-duty gasoline vehicles based on chassis dynamometer and tunnel studies in Shanghai, China," Atmospheric Environment, vol. 169, pp. 193-203, 2017.

[55] C. John, R. Friedrich, J. Staehelin, K. Schläpfer, and W. A. Stahel, "Comparison of emission factors for road traffic from a tunnel study (Gubrist tunnel, Switzerland) and from emission modeling," Atmospheric Environment, vol. 33, no. 20, pp. 3367-3376, 1999.

[56] W. R. Pierson, A. W. Gertler, N. F. Robinson et al., "Realworld automotive emissions-summary of studies in the Fort Mchenry and Tuscarora mountain tunnels," Atmospheric Environment, vol. 30, no. 12, pp. 2233-2256, 1996.

[57] China Statistics Press, Shenzhen Statistics Bureau and NBS Survey Office in Shenzhen, Shenzhen Statistical Yearbook, China Statistics Press, Beijing, China, 2015.

[58] Department of Urban Surveys, NBS, China City Statistical Yearbook, China Statistics Press, Beijing, China, 2015.

[59] L. Wang, "Motor vehicle exhaust in shenzhen and the research of its influence to the atmospheric environment quality," Thesis, Xiangtan University, Hunan, China, 2007.

[60] P. Guo, N. Ma, G. C. Chen, Q. Qiao, Y. Qin, and X. Wei, “A study on the vehicle emission factors in Chongqing," Journal of Southwest University (Natural Science Edition), vol. 31, no. 11, pp. 108-113, 2009.

[61] J. Wang, "Research on the discharging factor of vehicles in Xiamen," Modern Scientific Instruments, vol. 6, pp. 61-64, 2005.

[62] J. C. Xu, "Research and application of real-world vehicle emission characteristic," Thesis, Wuhan University of Technology, Wuhan, China, 2006.

[63] N. Zhang, "Study on emission characteristics of traffic pollutant in Foshan city," Thesis, Beijing Technology and Business University, Beijing, China, 2010.

[64] K. K. Liu, "The study on the characteristics of CO pollution of motor vehicle emissions in typical urban road," Thesis, Beijing Forestry University, Beijing, China, 2010.

[65] Q. R. Zhu, Y. H. Liu, W. L. Zeng, W. J. Xu, and M. Huang, "Research on distribution characteristics of motor vehicle exhaust emissions based on GPS floating car method," Research of Environmental Sciences, vol. 24, no. 10, pp. 10971103, 2011.

[66] X. X. Li, "Research on characteristics of vehicle exhaust pollution and its abatement control measures in Hangzhou," Thesis, Zhejiang University, Hangzhou, China, 2013.

[67] K. Wang, "Vehicle exhaust pollution estimates and analysis in huhhot," Thesis, Inner Mongolia University of Technology, Huhhot, China, 2014.

[68] K. Q. Yang, "The study of Xi'an motor vehicle exhaust emission quantitative simulation," Thesis, Chang'an University, Xi'an, China, 2015. 